This item was submitted to Loughborough's Research Repository by the author.

Items in Figshare are protected by copyright, with all rights reserved, unless otherwise indicated.

\title{
Vibrational power transmission in curved beams
}

PLEASE CITE THE PUBLISHED VERSION

PUBLISHER

(C) Academic Press / Elsevier

VERSION

AM (Accepted Manuscript)

LICENCE

CC BY-NC-ND 4.0

REPOSITORY RECORD

Walsh, Stephen J., and R.G. White. 2010. "Vibrational Power Transmission in Curved Beams". figshare. https://hdl.handle.net/2134/6482. 
This item was submitted to Loughborough's Institutional Repository (https://dspace.lboro.ac.uk/) by the author and is made available under the following Creative Commons Licence conditions.

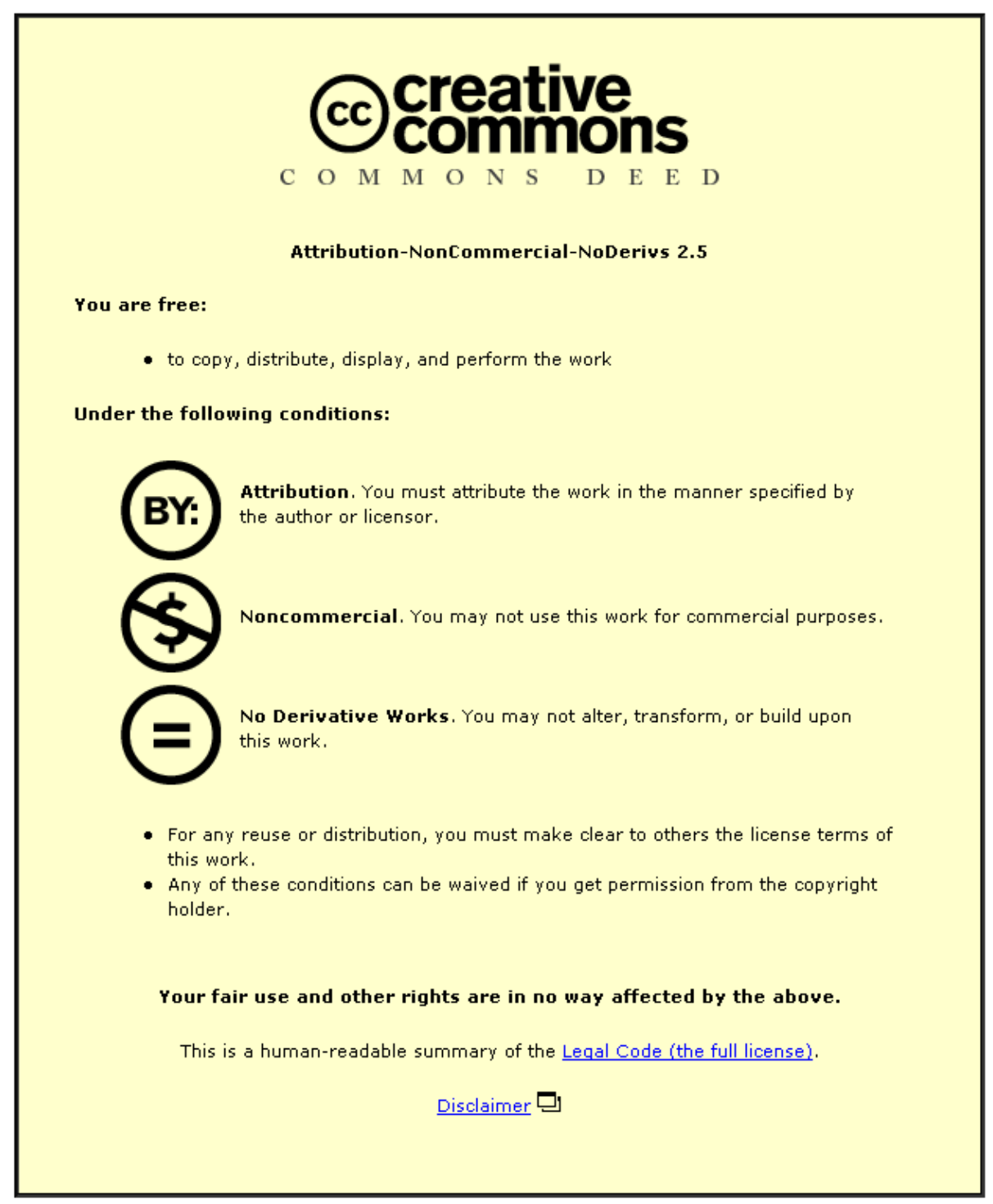

For the full text of this licence, please go to: http://creativecommons.org/licenses/by-nc-nd/2.5/ 
VIBRATIONAL POWER TRANSMISSION IN CURVED BEAMS

S.J. Walsh

Department of Aeronautical and Automotive Engineering, Loughborough University, Loughborough ${ }_{2}$ LE11 3TU, England and

R.G. White

Department of Aeronautics and Astronautics

University of Southampton, Southampton, $\mathrm{SO}_{3} 1 \mathrm{BJ}_{\text {, }}$ England

(Received 17 June 1999, and in final form 29 Noventber 1999)

4 Copies Submitted

44 Manuscript pages

9 Figures

6 Tables

RUNNING HEADLINE: Power Transmission in Curved Beams

ADDRESS FOR CORRESPONDENCE:

Dr S.J. Walsh

Department of Aeronautical and Automotive Engineering

Loughborough University

Loughborough, LE11 3TU. UK 


\begin{abstract}
Previous research into structural vibration transmission paths has shown that it is possible to predict vibrational power transmission in simple beam and plate structures. However, in many practical structures transmission paths are composed of more complex curved elements; therefore, there is a need to extend vibrational power transmission analyses to this class of structure. In this paper, expressions are derived which describe the vibrational power transmission due to flexural, extensional and shear types of travelling wave in a curved beam which has a constant radius of curvature. By assuming sinusoidal wave motion, expressions are developed which relate the time-averaged power transmission to the travelling wave amplitudes. The results of numerical studies are presented which show the effects upon power transmission along a curved beam of: (i) the degree of curvature; and (ii) various simplifying assumptions made concerning beam deformation.
\end{abstract}




\section{INTRODUCTION}

Unwanted vibration in ships, aircraft and buildings is often caused by the operation of machinery installed within the structure. The best to reduce the unwanted vibration is to modify the source and isolate it from the supporting structure. However, if the problem persists the vibration transmission characteristics through the structure from the source connection points to the area of unacceptable vibration levels must be examined, and appropriate vibration control procedures undertaken. For example, Figure 1 shows a typical machinery installation in a ship which consists of a machine mounted on a suspension system which is attached to the main structure of the vessel. In addition to the primary connection at the machinery seating, there will also be structural connections through the pipework, control linkages and exhaust system and an acoustic connection through the air or surrounding medium. Each of these connections provides a flanking path for the vibrational energy. Thus the vibration transmission and ultimate noise radiation from a machine will involve the investigation of several parallel transmission paths. Vibrational power transmission analysis techniques allow the direction of propagation of vibrational energy to be determined, and a magnitude to be assigned to each path.

\section{in order to}

$\angle$ TQ characterise acoustic transmission paths, acoustic intensity measurement methods have already been developed, and hence are not considered in this paper. Previous research into structural transmission paths has shown that it is possible to predict vibrational power transmission in simple beam and plate structures. More recently transmission through pipes with bends, branches and discontinuities has been studied [1], which has led to useful design rules concerning the position and size of pipe supports for minimum power transmission. However, in many practical structures transmission paths are composed of more complex curved elements. Therefore, there is a need to extend power transmission analysis to this class of structure.

Wave motion in a curved beam with constant radius of curvature has been considered by Love [2] who assumed that the centre-line remains unextended during flexural motion, whilst flexural behaviour is ignored when considering extensional motion. Using these assumptions the vibrational behaviour of 
complete or incomplete rings has been considered by many researchers who are interested in the low frequency behaviour of arches and reinforcing rings [3]. In reference [2] Love also presented equations for thin shells which include the effects of extension of the mid-surface during bending motion. Soedel [4] reduced these to equations applicable to a curved beam of constant radius of curvature. In an alternative approach, Graff [5] derived these equations from first principles and also constructed frequency-versus-wave number and wave speed-versus-wave number graphs. Philipson [6] derived a set of equations of motion which included extension of the central line in the flexural wave motion, and also rotary inertia effects. In a development analogous to that of Timoshenko for straight beams, Morley [7] introduced a correction for radial shear when

$L \quad$ considering the vibration of curved beams. Graff later presented frequency versus-wave number and wave speed-versus-wave number data for wave motion in a curved beam, when higher order effects are included [8]. More recently Walsh and White [9] presented formulae for the point and cross mobilities of 'semi-infinite' curved beams based upon theoretical and experimental studies.

In this paper, expressions for vibrational power transmission in a curved $S_{L}$ beam are derived from first principles. In the next Section two sets of governing equations for wave motion in a curved beam are presented, both of which include coupled extensional-flexural motion. The first set is based upon a reduction of Love's thin shell equations mentioned above. The second set is

$>_{h}$ based upon a reduction of Flügge's thin shell equations [10]. In $\$$ ection three, the $S$ expressions for stresses and displacements presented in Section two are used to derive formulae for vibrational power transmission in terms of centre-line displacements. By assuming sinusoidal wave motion, expressions are developed which relate the time-averaged power transmission to the extensional and $S_{L}$ flexural travelling wave amplitudes. In Section four, a correction for rotary intertia is introduced by allowing the elements of the beam to undergo rigid body

$S_{L}$ rotation in addition to lateral translation. Later in the Section, it is assumed the elements of the beam are also subjected to radial shearing stresses, and hence undergo shear deformation. The results of numerical studies of these expressions are presented which show the effects upon wave motion and power 
transmission of: (i) the degree of curvature; and (ii) the various simplifying assumptions made concerning the beam deformation.

\section{WAVE MOTION IN CURVED BEAMS}

\subsection{INTRODUCTION}

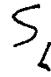

In this @ection the equations of motion for a curved beam are presented where the centre-line of the beam forms a plane of constant radius of curvature. The cross-section of the beam is uniform and symmetrical about a plane and it is also assumed that there is no motion perpendicular to the plane. It is also assumed that the beam material is linearly elastic, homogeneous, isotropic and

$S_{L}$ continuous. The results of two different theories are presented in this Section, both of which can be classed 'simple bending' or 'thin shell' theories, and which include extension of the centre-line during flexural motion. One set of expressions can be obtained by reduction of Love's thin shell equations $[4,10]$ and converting from generalised curvilinear co-ordinates to polar co-ordinates; alternatively, the expressions can be derived from first principles [5]. A second set of expressions can be obtained by reduction of Flügge's thin shell equations [10]. Of the many different shell theories these two were chosen: (i) because they are two of the most widely used sets of equations, and (ii) because expressions for vibrational power transmission in circular cylindrical shells [11] and arbitrary shaped shells [12] have already been published based upon Flügge's and Love's equations, respectively.

\subsection{THE GOVERNING EQUATIONS}

Consider a portion of a curved beam, as shown in Figure 2. The circumferential co-ordinate measured around the centre-line is $s$, while the outward pointing normal co-ordinate from the centre-line is $z$, and the general radial co-ordinate is $\mathrm{r}$. A complete list of notation is given in Appendix B. The centre-line is defined as the locus of centroids of each cross-sectional element. The tangential and radial displacements of a material point are $U(r, s, t)$ and $W$ 
$(r, s, t)$, respectively. For small displacements of thin beams the following assumptions, known as "Love's first approximation" in classical shell theory, can be made [10]:

(i) the thickness of the beam in the plane of curvature is small compared with other dimensions, for example, the radius of curvature;

(ii) strains and displacements are sufficiently small so that second- and higherorder magnitude terms in the strain-displacement relationships may be neglected in comparison with first-order terms;

(iii) the transverse normal strain is small compared to the other normal strains and may be neglected;

(iv) normals to the undeformed middle-surface remain straight and normal to the deformed middle-surface and suffer no extension.

The fourth assumption is known as Kirchoff's hypothesis and imposes the following linear relationships between the displacements of a material point and components of displacement at the undeformed centre-line:

$$
\begin{gathered}
U(r, s, t)=u(R, s, t)+z \phi(s, t), \\
W(r, s, t)=w(R, s, t),
\end{gathered}
$$

where $\mathrm{u}$ and $\mathrm{w}$ are the components of displacement at the centre-line in the tangential and radial directions, respectively, $\phi$ is the rotation of the normal to the centre-line during deformation:

$$
\phi=\frac{\frac{\mathrm{u}}{\mathrm{R}}-\frac{\partial \mathrm{w}}{\partial \mathrm{s}},}{\left(\begin{array}{c}
\text { angle of } \\
\text { curvature }
\end{array}\right)\left(\begin{array}{c}
\text { rotational displacement } \\
\text { of straignt beam }
\end{array}\right)}
$$

and $\mathrm{W}$ is independent of $\mathrm{z}$ and is completely defined by the centre-line component $w$. Substituting equations (1a) and (1b) into the strain-displacement equations of three-dimensional elasticity theory gives the following relation for total circumferential strain: 


$$
\mathrm{e}_{\mathrm{s}}=\frac{1}{\left(1+\frac{\mathrm{z}}{\mathrm{R}}\right)}\left(\varepsilon_{\mathrm{s}}+\mathrm{z} \beta_{\mathrm{s}}\right)
$$

where $\varepsilon_{\mathrm{s}}$ is the in-plane (extensional) strain and $\beta_{\mathrm{s}}$ is the bending strain (mid-surface change in curvature). Equation (3) is the strain-displacement equation of Flügge [10]. If the term $\frac{Z}{R}$ in equation (3) is neglected with respect to unity in the denominator, the strain-displacement equation of Love is obtained [10]. Since the radial stress component, $\sigma_{\mathrm{r}}$ is assumed negligible, the transverse strain, $\varepsilon_{\mathrm{r}}$, is zero, and as a consequence of Kirchoff's hypothesis the transverse shear strain, $\gamma_{\mathrm{sr}^{\prime}}$ is zero.

Assuming the material to be linearly elastic, the circumferential and transverse stress-strain relationships are given by Hooke's Law. But from Kirchoff's hypothesis the shear strain, $\gamma_{\mathrm{sr}}$, is zero, thus the shear stress, $\sigma_{\mathrm{sr}}$, is zero. However, these stresses cannot be zero since they are related to the transverse shearing forces needed for equilibrium, which is an unavoidable inconsistency in simple bending theory. From Hooke's Law, the radial stress is given by $\sigma_{\mathrm{r}}=v \sigma_{\mathrm{S}}$ where $v$ is Poisson's ratio, but Love's third assumption is that $\sigma_{\mathrm{r}}$ is zero, which is another contradiction in the shell theory considered here. The straindisplacement expressions and stress-strain equations of the Love and Flügge based theories are listed in Table 1.

Assuming the material to be homogeneous and isotropic, the Young's modulus, E, shear modulus, G, and Poisson's ratio, v, can be treated as constants. Thus, by integrating the stresses over the beam thickness, force and moment resultants are obtained. Although the transverse shear stress, $\sigma_{\mathrm{sr}}$ is zero, a nonvanishing shear resultant, $Q$, is defined as the integral across the thickness of the transverse shear stress. The circumferential force, $N$, bending moment, $M$, and shear force, Q, of the Love and Flügge based theories are listed in Table 2. Figure 3 shows the sign convention of force resultants on an elemental slice of a curved beam. 


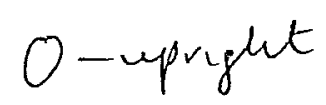

Equations of motion for a curved beam are presented in [5]. These equations are derived in terms of the radian parameter $\theta$. By applying the substitutions, $s=R \theta$ and $\frac{\partial f}{\partial s}=\frac{1}{R} \frac{\partial f}{\partial \theta}$, equations of motion are obtained which are expressed in terms of the circumferential length, s. Alternatively the equations of motion can be obtained from Love based equations for a cylindrical shell [10].

Flügge ${ }^{-}$based equations of motion for a curved beam also assume the simplifying assumptions of "Love's first approximation". However, because of the stage in the derivation at which these approximations are introduced these equations also implicitly assume that there is a shift of neutral axis location due to beam curvature. For this paper, the Flügge based equations of motion were obtained by reduction of the equations of motion for a circular cylindrical shell presented in [9]. The Lové̄and Flüggé based equations of motion are listed in Table 3 .

An harmonic solution of the equations of motion can be obtained by assuming that extensional and flexural sinusoidal waves propagate in the circumferential direction and can be represented respectively by:

$$
\begin{aligned}
& w(s, t)=\tilde{A} @[\exp [(\omega t-k s)], \\
& u(s, t)=\widetilde{B} \exp [(\omega t-k s)]
\end{aligned}
$$

where $\widetilde{A}$ and $\widetilde{B}$ are the complex wave amplitudes. Substituting these harmonic

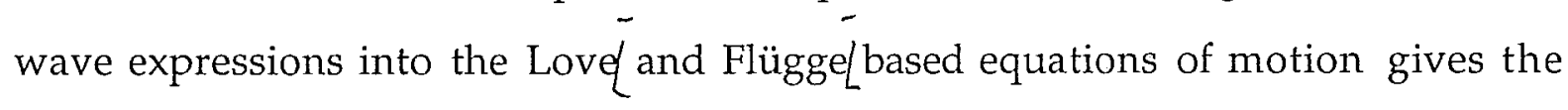
harmonic form of the equations of motion which are listed in Table 4.

\subsection{COMPUTER SIMULATION}

For a given real wavenumber, $k$, the harmonic equations of motion can be solved to find the corresponding radian frequency, $\omega$, and complex wave ? $\bar{L} \bar{L}$ amplitude ratio $\left(\frac{\tilde{\mathrm{B}}}{\tilde{\mathrm{A}}}\right)$. Both the Love $\bar{L}$ and Flügge $\mathcal{L}$ based sets of equations were 
solved using computer programs written in the matrix analysis language MATLAB. The simulated beam was chosen to have the material properties of typical mild steel strip beams used for laboratory experiments. The material properties were:

$\begin{array}{lll}\text { Young's modulus } & \mathrm{E}=207.0 \times 10^{9} & \left(\mathrm{~N} / \mathrm{m}^{2}\right), \\ \text { Shear modulus } & \mathrm{G}=79.6 \times 10^{9} & \left(\mathrm{~N} / \mathrm{m}^{2}\right), \\ \text { Density } & \rho=7850.0 & \left(\mathrm{~kg} / \mathrm{m}^{3}\right) .\end{array}$

The beam thickness, $\mathrm{h}$, was set at $10 \mathrm{~mm}$ and thus, approximately at the same thickness $(6-7 \mathrm{~mm})$ as typical experimental beams. For ease of computation the beam width, b, was set to unity (i.e. $1.0 \mathrm{~m}$ ) rather than the more typical $0.05 \mathrm{~m}$ width of experimental beams, since in the theoretical model it is assumed that there is no motion in the direction of the width of the beam. Four different radii of curvature were investigated, which were represented in terms of the nondimensional thickness to radius of curvature ratio, $\frac{h}{R}$. These ratios were $\left(\frac{1}{10}, \frac{1}{100}, \frac{1}{1000}\right.$ and $\left.\frac{1}{10000}\right)$.

\subsection{RESULTS}

The solution of the Lové and Flüggę based equations of motion for a curved beam was obtained by substituting a given real valued wavenumber into the equations of motion and, hence, calculating the two real valued radian frequencies. Based upon the Love equations of motion, Figures 4 and 5 show the wave motion characteristics for the beam with the severest thickness to $^{\text {radius of }}$ curvature ratio (i.e. $h / R=1 / 10$ ). Figure 4 shows the relationship between wave number and frequency, where the frequency data have been plotted on the horizontal axis and the wavenumber data have been plotted on the vertical axis. The frequency range is represented in terms of the non-dimensional frequency 
parameter $\Omega=\frac{\omega R}{c_{0}}$, where $c_{0}$ is the phase velocity of extensional waves in a straight bar and the wave number range is represented in terms of the nondimensional wave number, $\mathrm{kR}$. It can be seen that two types of wave exist : one involving predominantly flexural motion and the other predominantly extensional motion. The predominantly extensional wave "cuts-on" when the non-dimensional frequency, $\Omega$, is equal to one. This is the familiar "ring frequency" of cylindrical shell dynamics, and is the frequency when the wavelength of extensional waves in a straight rod is equal to the circumference, $2 \pi \mathrm{R}$. It can be seen in Figure 4 that above the ring frequency the dispersion relationship is essentially that of quasi-longitudinal waves in a straight rod. For the predominantly flexural wave there is a special root at zero frequency (and zero group velocity) when the non-dimensional wave number, $k R$, is equal to one. This situation occurs when the wavelength of the predominantly flexural wave is equal to the circumference, $2 \pi R$. For wave numbers of value just less than the special root, $k R=1$, it can be seen in Figure 4 that there is a frequency region where the dispersion curve of the predominantly flexural wave has negative slope and, hence, negative group velocity. Although highly unusual, waves with negative group velocity have also been predicted in cylindrical shell sections [13]. For non-dimensional wavenumbers of value less than $k R=0.6$ the dispersion curve reverts to a positive gradient. For wave numbers of value greater than the special root, $k R=1$, it can be seen in Figure 4 that as the frequency increases the dispersion curve for the predominantly flexural wave becomes increasingly like the dispersion curve of purely flexural waves in a straight Euler-Bernoulli beam. As the frequency increases, a frequency is reached 
where both wave types have the same wavenumber. This occurs when $\frac{\omega K}{c_{0}}=1$, where $\mathrm{K}$ is the radius of gyration of the beam. This is when the wavelength of extensional waves in a straight rod is equal to $2 \pi \times$ radius of gyration of the curved beam (i.e. $\lambda_{\mathrm{ex}}=2 \pi \mathrm{K}$ ). Dispersion curves for the beams with the less severe thickness to radius of curvature ratios $\left(\frac{1}{100}, \frac{1}{1000}\right.$ and $\left.\frac{1}{10000}\right)$ showed a similar pattern of behaviour. Indeed, with an astute choice of non-dimensional frequency axis then all four dispersion curves for a particular wave type can be made to lie on the same line. For example, in Figure 4 a non-dimensional frequency axis of $\Omega=\frac{\omega R}{c_{0}}$ was chosen. In this case all four dispersion curves for the predominantly extensional wave lie on the line marked with "o" symbols. Of course, when the data are displayed against a dimensional frequency axis, such as cycles per second $(\mathrm{Hz})$, then as the radius of curvature increases the beam behaviour becomes increasingly similar to that of a straight beam or rod. In the limit, the dispersion curves approach the familiar straight beam relationships illustrated in reference [5].

The predominantly flexural wave will involve extensional motion as well as flexural motion. Conversely, the predominantly extensional wave will involve flexural motion as well as extensional motion. This wave amplitude relationship is shown graphically in Figure 5, displayed over the same frequency range as used in Figure 4. The predominantly flexural wave amplitude ratio is represented by the ratio of the extensional to flexural motion, whilst the predominantly extensional wave amplitude ratio is represented by the ratio of 
the flexural to extensional motion. It can be seen in Figure 5 that at the cut-on frequency, $\Omega=1$, the predominantly extensional wave is, in fact, dominated by flexural motion. Similarly at the cross-over frequency, $\frac{\omega \mathrm{K}}{c_{0}}=1$, the predominantly extensional wave is dominated by flexural motion. In the frequency region between these two points the wave is dominated by extensional motion. At the special root, $k R=1$, the predominantly flexural wave consists of equal flexural and extensional motion. For non-dimensional frequencies greater than the special root $k R=1$, as the frequency increases the wave becomes increasingly flexural in nature until the cross-over frequency, $\frac{\omega K}{c_{0}}=1$, when extensional motion again dominates. For non-dimensional wavenumbers less than $\mathrm{kR}=1$, the predominantly flexural wave contains greater extensional motion than flexural motion. The relative phase angle between the flexural and extensional amplitudes, $A$ and $B$, has not been shown. However, inspection of the harmonic form of the equations of motion shows that for real valued frequencies and wavenumbers the complex wave amplitudes $\tilde{\mathrm{A}}$ and $\widetilde{B}$ will differ by $\pm \mathrm{i}$. Thus, the displacements have a relative phase angle of \pm 90 degrees.

The corresponding characteristics of wave motion in curved beams were

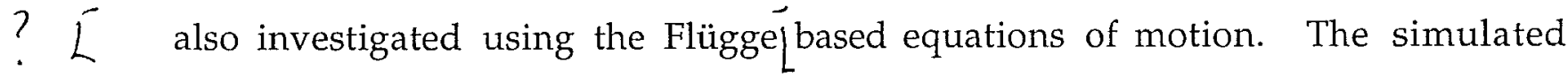
beams were given identical dimensions and material properties as the beams used previously for the Love [based analysis. The results of this investigation revealed that both theories predict the identical wave behaviour in the low and medium frequency regions and that only slight differences occur at high frequencies (in the frequency region near $\frac{\omega \mathrm{K}}{\mathrm{c}_{\mathrm{O}}}=1$ ). 


\subsection{VIBRATIONAL POWER TRANSMISSION IN CURVED BEAMS}

\subsection{THEORY}

In this Section the expressions for displacements and stresses presented in $S$ Section two are used to derive the structural intensity and power transmission due to flexural and extensional travelling waves in a curved beam. The structural intensity expressions are formulated in terms of displacements at the centre-line. By assuming sinusoidal wave motion, expressions are developed which relate the time-averaged power transmission to the flexural and extensional travelling wave amplitudes. The effect of curvature upon power transmission is investigated using the same four beams whose wave motion

$S$ characteristics were studied in Section two.

Structural intensity in the circumferential direction of a curved beam is given by [14]:

$$
\begin{aligned}
& \mathrm{I}_{\mathrm{s}}=\left(-\sigma_{\mathrm{s}} \frac{\partial \mathrm{U}}{\partial \mathrm{t}}\right)+\left(-\sigma_{\mathrm{sr}} \frac{\partial \mathrm{W}}{\partial \mathrm{t}}\right) . \\
& \left(\begin{array}{c}
\text { intensity due to } \\
\text { circumferential stress }
\end{array}\right)\left(\begin{array}{c}
\text { intensity due to } \\
\text { radial shear stress }
\end{array}\right)
\end{aligned}
$$

$L$, By integrating across the beam thickness, power transmission per unit length in the circumferential direction is obtained [15]:

$$
P_{S}=\int_{-h / 2}^{h / 2} I_{S} d z
$$

Substituting the circumferential stress-strain relation and Love's straindisplacement expression into equation (7), the power transmission due to circumferential stress is obtained. (A full derivation is given in Appendix A.) By analogy to power transmission in a straight beam this is expressed in terms of an extensional component and a bending moment component, respectively: 


$$
\begin{aligned}
& \mathrm{P}_{\mathrm{e}}=-\mathrm{SE}\left[\frac{\mathrm{w}}{\mathrm{R}}+\frac{\partial \mathrm{u}}{\partial \mathrm{s}}\right] \quad \frac{\partial \mathrm{u}}{\partial \mathrm{t}}, \\
& \left(\begin{array}{c}
\text { - circumferential } \\
\text { force }
\end{array}\right) \quad\left(\begin{array}{c}
\text { circumferential } \\
\text { velocity }
\end{array}\right) \\
& P_{b m}=-E I\left[\frac{\partial}{\partial s}\left(\frac{u}{R}-\frac{\partial w}{\partial s}\right)\right]\left[\frac{\partial}{\partial t}\left(\frac{u}{R}-\frac{\partial w}{\partial s}\right)\right] . \\
& \left(\begin{array}{c}
\text { - bending } \\
\text { moment }
\end{array}\right) \quad\left(\begin{array}{c}
\text { rotational } \\
\text { velocity }
\end{array}\right)
\end{aligned}
$$

Although the transverse shear stress, $\sigma_{\mathrm{sr}}$ is negligible under Love's first approximation, the power transmission due to transverse shear stress can be evaluated from the non-vanishing shear force, $Q$, because the radial displacement, W, does not vary across the beam thickness. Again, by analogy to

${ }^{2} L$ power transmission in a straight beam, this is expressed as a shear force component:

$$
\begin{aligned}
& P_{\text {sf }}=-E I\left[\frac{\partial^{2}}{\partial s^{2}}\left(\frac{u}{R}-\frac{\partial w}{\partial s}\right)\right] \quad \frac{\partial w}{\partial t} . \\
& \text { (- shear force) (radial velocity) }
\end{aligned}
$$

Thus, total power transmission in the circumferential direction is given by:

$$
P_{s}=P_{e}+P_{b m}+P_{s f}
$$

L Using the Flügge/based strain-displacement expression, equation (3), the following power transmission expressions are obtained for the extensional, bending moment and shear force components (a full derivation is given in Appendix A):

$$
\begin{gathered}
P_{e}=-\left[E S\left(\frac{W}{R}+\frac{\partial u}{\partial s}\right)+\frac{E I}{R}\left(\frac{w}{R^{2}}+\frac{\partial^{2} w}{\partial s^{2}}\right)\right] \\
\left(\begin{array}{c}
\text { circumferential } \\
\text { force }
\end{array}\right) \\
P_{b m}=E I\left[\frac{w}{R^{2}}+\frac{\partial^{2} w}{\partial s^{2}}\right] \quad \frac{\partial}{\partial t}\left(\frac{u}{R}-\frac{\partial w}{\partial s}\right),
\end{gathered}
$$




$$
\begin{gathered}
\left(\begin{array}{c}
\text { - bending } \\
\text { moment }
\end{array}\right) \quad\left(\begin{array}{c}
\text { rotational } \\
\text { velocity }
\end{array}\right) \\
P_{\text {sf }}=\operatorname{EI}\left[\frac{\partial}{\partial s}\left(\frac{w}{R^{2}}+\frac{\partial^{2} W}{\partial s^{2}}\right)\right] \\
(- \text { shear force) }
\end{gathered} \underset{\text { (radial velocity) }}{\frac{\partial w}{\partial t} .}
$$

The total power transmission in the circumferential direction is given by equation (11). Equations (12) and (13) can be re-arranged by noting that the $\frac{E I}{R}$ term in the extensional component, equation (12), is exactly cancelled by an equivalent expression in the bending moment component, equation (13), giving modified power transmission expressions:

$$
\begin{aligned}
& P_{e}=-E S\left[\frac{W}{R}+\frac{\partial u}{\partial s}\right] \quad \frac{\partial u}{\partial t},
\end{aligned}
$$

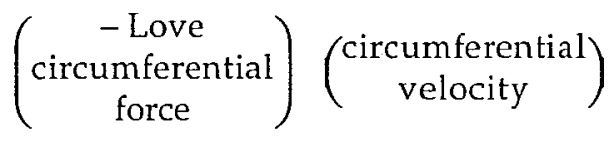

$$
\begin{aligned}
& \mathrm{P}_{\mathrm{bm}}=\mathrm{EI}\left[\frac{\mathrm{w}}{\mathrm{R}^{2}}+\frac{\partial^{2} \mathrm{w}}{\partial \mathrm{s}^{2}}\right] \quad \frac{\partial}{\partial \mathrm{t}}\left(-\frac{\partial \mathrm{w}}{\partial \mathrm{s}}\right) . \\
& \left.\left(\begin{array}{c}
- \text { Flügge bending } \\
\text { moment }
\end{array}\right) \text { ( } \begin{array}{c}
\text { straight beam } \\
\text { rotational velocity }
\end{array}\right)
\end{aligned}
$$

The total power transmission in the circumferential direction is given by the sum of equations (14), (15) and (16). For ease of reference these equations are also listed in Table 5.

To obtain a relationship between vibrational power transmission and the amplitude of the waves travelling in the beam assume that extensional and flexural sinusoidal waves propagate in the positive $s$ direction and can be represented respectively by :

$$
\begin{aligned}
& w(s, t)=\operatorname{Re}\left\{\tilde{A}(\exp )\left[(i)\left(\omega t-k_{A} s\right)\right]\right\} \\
& =A \cos \left[\omega t-k_{A} S+\theta_{A}\right] \text {, } \\
& \left.u(s, t)=\operatorname{Re}\left\{\tilde{B}\left(e^{\exp }\right) \hat{G}\left(\omega t-k_{B} s\right)\right]\right\} \\
& =B(\cos )\left[\omega t-k_{B} s\right] \text {, }
\end{aligned}
$$


where $\theta_{\mathrm{A}}$ is the relative phase angle between the flexural and extensional L motions. As noted in Section 2.4 this relative phase angle is plus or minus 90 degrees. Substituting the harmonic wave expressions equations (17) and (18), into the Lovejbased power transmission equations, (8) - (10), gives expressions for the power transmission in the circumferential direction in terms of the travelling wave amplitudes $A$ and $B$, and the relative phase angle $\theta_{A}$. The extensional, bending moment and shear force components are respectively:

$$
\begin{gathered}
P_{e}=E S\left[\frac{\omega A A}{R} \cos \left[\omega t-k_{A} s+\theta_{A}\right] \overparen{\sin }\left[\omega t-k_{B} s\right]+\omega k_{B} B^{2}\left(\sin ^{2}\left[\omega t-k_{B} s\right]\right],\right. \\
P_{b m}=E I\left[\frac{\omega k_{B} B^{2}}{R^{2}} \sin ^{2}\left[\omega t-k_{B} s\right]+\frac{\left(k_{B}+k_{A}\right) \omega k_{A} B A}{R}\right. \\
(\sin )\left[\omega t-k_{B} s\right]\left[\cos \left[\omega t-k_{A} s+\theta_{A}\right]+\omega k_{A}^{3} A^{2} \cos ^{2}\left[\omega t-k_{A} s\right]\right], \\
P_{s f}=E I\left[-\frac{k_{B}^{2} \omega B A}{R} \cos \left[\omega t-k_{B} s\left(\sin \left[\omega t-k_{A} s+\theta_{A}\right]\right.\right.\right. \\
\left.\quad+k_{A}^{3} A^{2} \omega \sin ^{2}\left[\omega t-k_{A} s+\theta_{A}\right]\right] .
\end{gathered}
$$

Similarly, substituting the harmonic wave expressions (17) and (18) into the Flügge [based power transmission expressions, (14) - (16), gives the power transmission in terms of the travelling wave amplitudes $A$ and $B$ :

$$
\begin{aligned}
& P_{e}=E S\left[\frac { B A \omega } { R } \Leftrightarrow \left[\operatorname { C o s } \left[\omega t-k_{A} s+\theta_{A} \int \sin \left[\omega t-k_{B} s\right]\right.\right.\right. \\
& +k_{B} B^{2} \omega\left(\sin ^{2}\left[\omega t-k_{B} s\right]\right], \\
& P_{b m}=E_{I} A^{2} k_{A} \omega k_{A}^{2}-\frac{1}{R^{2}} \widehat{\cos }^{2}\left[\omega t-k_{A} s+\theta_{A}\right],
\end{aligned}
$$




$$
P_{s f}=E I A^{2} k_{A} \omega\left(k_{A}^{2}-\frac{1}{R^{2}}\right) \sin ^{2}\left[\omega t-k_{A} s+\theta_{A}\right]
$$

The total power transmission is given by the sum of the extensional, bending moment and shear force components.

L So far, expressions have been developed for power transmission which are functions of both position and time. For sinusoidal wave motion it is useful to develop time-averaged power transmission defined by:

$$
\left\langle\mathrm{P}_{\mathrm{S}}\right\rangle_{\mathrm{t}}=\frac{1}{\mathrm{~T}} \int_{-\mathrm{T} / 2}^{\mathrm{T} / 2} \mathrm{P}_{\mathrm{s}}(\mathrm{s}, \mathrm{t}) \mathrm{d} \mathrm{d},
$$

? L where $\mathrm{T}$ is the period of the signal. Thus, the Love ${ }^{b}$ based harmonic power transmission equations, (19) - (21), become:

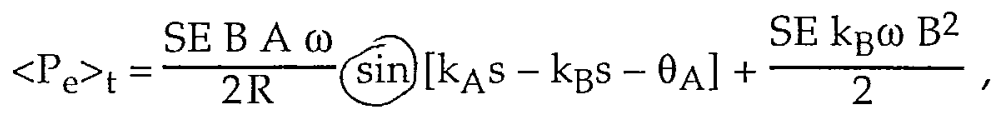

$$
\begin{aligned}
& <\mathrm{P}_{b m}>_{t}=E I\left[\frac{\omega k_{B} B^{2}}{2 R^{2}}+\frac{\omega k_{A} B A}{2 R}\left(k_{B}+k_{A}\right) \circlearrowleft \sin \left[k_{A} s-k_{B} s-\theta_{A}\right]+\frac{\omega k_{A}^{3} A_{A}^{2}}{2}\right], \\
& \left\langle\mathrm{P}_{\mathrm{sf}}>_{t}=\mathrm{EI}\left[-\frac{\mathrm{k}_{\mathrm{B}}^{2} \omega \mathrm{BA}}{2 \mathrm{R}}\left[\mathrm{k}_{\mathrm{B}} \mathrm{s}-\mathrm{k}_{\mathrm{A}} \mathrm{s}+\theta_{\mathrm{A}}\right]+\frac{\mathrm{k}_{\mathrm{A}}^{3} \omega \mathrm{A}^{2}}{2}\right] .\right.
\end{aligned}
$$

Similarly, the Flügge [based harmonic power transmission equations, (22) - (24), become:

$$
\begin{aligned}
<\mathrm{P}_{\mathrm{e}}>_{\mathrm{t}}= & \frac{\mathrm{ESBA} \omega}{2 \mathrm{R}}\left(\sin \left[\mathrm{k}_{\mathrm{A}} \mathrm{s}-\mathrm{k}_{\mathrm{B}} \mathrm{s}-\theta_{\mathrm{A}}\right]+\frac{E S \mathrm{k}_{\mathrm{B}} \omega \mathrm{B}^{2}}{2},\right. \\
<\mathrm{P}_{\mathrm{bm}}>_{\mathrm{t}} & =\frac{\mathrm{EI} \mathrm{A}^{2} \omega \mathrm{k}_{\mathrm{A}}}{2}\left(\mathrm{k}_{\mathrm{A}}{ }^{2}-\frac{1}{\mathrm{R}^{2}}\right), \\
<\mathrm{P}_{\mathrm{sf}}>_{\mathrm{t}} & =\frac{\mathrm{EI} \mathrm{A}^{2} \omega \mathrm{k}_{\mathrm{A}}}{2}\left(\mathrm{k}_{\mathrm{A}}{ }^{2}-\frac{1}{\mathrm{R}^{2}}\right) .
\end{aligned}
$$


For a curved beam there is interaction between the longitudinal and bending deformations leading to coupled extensional-flexural wave motion. This is unlike the situation for straight beams where purely longitudinal and purely flexural motion can exist independently. Using the Love and Flügge equations of motion for a curved beam it was shown that two types of elastic wave exist, one involving predominantly extensional motion, the other predominantly flexural motion. For a given harmonic wave of frequency, $\omega$, and wave number, $k$, the equations of motion were solved to find the associated extensional to flexural wave amplitude ratio $\left(\frac{B}{A}\right)$ and relative phase angle $\theta_{A}$. Thus, the time-averaged power transmission by a single harmonic wave is found by setting the wave numbers $k_{A}$ and $k_{B}$ equal to $k$, say, and using the

? L corresponding extensional to flexural wave amplitude ratio. For the Love ${ }^{\text {based }}$ power transmission equations, (26) - (28), this gives:

$$
\begin{gathered}
<\mathrm{P}_{\mathrm{e}}>_{\mathrm{t}}=\frac{\mathrm{ES} \omega \mathrm{kB} \mathrm{B}^{2}}{2}-\frac{\mathrm{ES} \omega \mathrm{BA}}{2 \mathrm{R}} \operatorname{Sin}\left[\theta_{\mathrm{A}}\right], \\
<\mathrm{P}_{\mathrm{bm}}>_{\mathrm{t}}=\mathrm{EI}\left[\frac{\omega \mathrm{kB} \mathrm{B}^{2}}{2 \mathrm{R}^{2}}+\frac{\omega \mathrm{k}^{3} \mathrm{~A}^{2}}{2}-\frac{\omega \mathrm{k}^{2} \mathrm{BA}}{\mathrm{R}} \operatorname{Sin}\left[\theta_{\mathrm{A}}\right]\right], \\
<\mathrm{P}_{\mathrm{sf}}>_{\mathrm{t}}=\frac{\mathrm{EI} \mathrm{k}^{3} \omega \mathrm{A}^{2}}{2}-\frac{\mathrm{EI} \omega \mathrm{k}^{2} \mathrm{BA}}{2 \mathrm{R}} \operatorname{Sin}\left[\theta_{\mathrm{A}}\right] .
\end{gathered}
$$

Similarly, time-averaged power transmission by a single harmonic wave using $?$ the Flügge [based equations, (29) - (31), is given by:

$$
\begin{gathered}
<\mathrm{P}_{\mathrm{e}}>_{\mathrm{t}}=\frac{\mathrm{ES} \mathrm{k \omega \textrm {B } ^ { 2 }}}{2}-\frac{\mathrm{ES} \omega \mathrm{BA}}{2 \mathrm{R}} \operatorname{Sin}\left[\theta_{\mathrm{A}}\right], \\
<\mathrm{P}_{\mathrm{bm}}>_{\mathrm{t}}=\frac{\mathrm{EI} \mathrm{A}^{2} \omega \mathrm{k}}{2}\left(\mathrm{k}^{2}-\frac{1}{\mathrm{R}^{2}}\right),
\end{gathered}
$$




$$
<\mathrm{P}_{\mathrm{sf}}>_{\mathrm{t}}=\frac{\mathrm{EI} \mathrm{A}^{2} \omega \mathrm{k}}{2}\left(\mathrm{k}^{2}-\frac{1}{\mathrm{R}^{2}}\right)
$$

Thus the total time-averaged power transmission by a single elastic wave in the circumferential direction is given by the sum of the extensional, bending moment and shear force components. Equations (32) - (37) are also listed in Table 6.

\subsection{RESULTS OF COMPUTER SIMULATION}

The power transmission expressions, (32) - (37), were programmed using the matrix analysis program, MATLAB. The simulated beams were chosen to

$S$ have the same dimensions and material properties as those used in the study of Fig $\left.\sigma_{1}\right)^{2}$ wave motion in Section two. Figure 6 shows the relationship between transmitted power ratio and frequency over the same non-dimensional $S$ frequency range as investigated in Section two. For the predominantly flexural wave the time-averaged transmitted power ratio is calculated by dividing the time-averaged power transmitted along a curved beam by a predominantly flexural wave (equations (32), (33) and (34), with $\mathrm{k}=\mathrm{k}_{\mathrm{B}}$, the predominantly flexural wave number) by the time-averaged power transmitted by a pure flexural wave travelling in a straight Euler-Bernoulli beam:

$$
\frac{\mathrm{P}}{\mathrm{P}_{\mathrm{f}}}=\frac{\left.\left.\left\langle\mathrm{P}_{\mathrm{e}}\right\rangle_{\mathrm{t}}+<\mathrm{P}_{\mathrm{bm}}\right\rangle_{\mathrm{t}}+<\mathrm{P}_{\mathrm{sf}}\right\rangle_{\mathrm{t}}}{\left.<\mathrm{P}_{\mathrm{f}}\right\rangle_{\mathrm{t}}}
$$

where $\left\langle\mathrm{P}_{\mathrm{f}}\right\rangle_{\mathrm{t}}=\mathrm{EI}_{\mathrm{f}} \mathrm{k}_{\mathrm{f}}^{3} \mathrm{~A}_{\mathrm{f}}^{2}$, where $\mathrm{k}_{\mathrm{f}}$ is the wavenumber and $\mathrm{A}_{\mathrm{f}}$, the wave amplitude of a purely flexural wave in a straight beam. For the predominantly extensional wave the transmitted power ratio is calculated by dividing the timeaveraged power transmitted along a curved beam by a predominantly extensional wave (equations (32), (33) and (34), with $\mathrm{k}=\mathrm{k}_{\mathrm{A}}$, the predominantly extensional wave number) by the time-averaged power transmitted by a purely extensional wave in a straight rod: 


$$
\frac{\mathrm{P}}{\mathrm{P}_{\mathrm{ex}}}=\frac{\left\langle\mathrm{P}_{\mathrm{e}}\right\rangle_{\mathrm{t}}+\left\langle\mathrm{P}_{\mathrm{bm}}\right\rangle_{\mathrm{t}}+\left\langle\mathrm{P}_{\mathrm{sf}}\right\rangle_{\mathrm{t}}}{\left\langle\mathrm{P}_{\mathrm{ex}}\right\rangle_{\mathrm{t}}}
$$

where $\left\langle\mathrm{P}_{\mathrm{ex}}\right\rangle=\mathrm{ES} \omega \mathrm{k}_{\mathrm{ex}} \mathrm{B}_{\mathrm{ex}}^{2}$. Considering first the power transmitted by the predominantly extensional wave, it can be seen in Figure 6 that below the ring $S$ frequency, $\Omega=1$, no power is transmitted. This agrees with the results of Section two where it was shown that below the ring frequency there is no predominantly ' $L$ extensional travelling wave motion. Above the ring frequency, but below the cross-over frequency, $\frac{\omega \mathrm{K}}{c_{\mathrm{O}}}=1$, it can be seen that the transmitted power ratio takes a value of 1.0. This indicates that the level of power transmitted along a curved beam by a predominantly extensional wave is the same as the level of power transmitted by a purely extensional wave travelling along a straight rod. Above the cross-over frequency, $\frac{\omega \mathrm{K}}{\mathrm{c}_{\mathrm{O}}}=1$, there is a divergence from straight beam behaviour. Considering now the power transmitted by the predominantly flexural wave, it can be seen in Figure 6 that at very low frequency there are three branches corresponding to the three dispersion curve branches shown in Figure 4. Following the uppermost branch it can be seen that at low frequency the transmitted power ratio is greater than 1.0. This indicates that more power is transmitted by a predominantly flexural wave travelling in a curved beam than by a corresponding purely flexural wave in a straight Euler-Bernoulli beam. However, as the frequency increases towards the ring frequency, $\Omega=1$, the transmitted power ratio reduces to 1.0. This indicates that a predominantly flexural wave travelling in a curved beam and a purely flexural wave travelling in a straight beam transmit the same amount of power. As the frequency increases this condition continues until the cross-over frequency, $\frac{\omega \mathrm{K}}{\mathrm{c}_{\mathrm{o}}}=1$, is reached. Above the cross-over frequency there is a divergence from straight beam behaviour. 


\subsection{THE EFFECT OF ROTARY INERTIA AND SHEAR DEFORMATION}

It is known that shear deformation and rotary inertia effects become significant for straight beams as the wave length approaches the thickness of the beam [16], and for cylindrical shells as the shell radius decreases [10]. Thus, the

Anltors objective in this section is to establish more complete equations for power transmission in a curved beam and to show under what conditions these S) specialise to the simple bending equations presented in section three.

\subsection{THE EFFECT OF ROTARY INERTIA}

Rotary inertia effects are included by considering each element of the beam to have rotary inertia $\left(\rho \mathrm{I} \frac{\partial^{2} \phi}{\mathrm{dt}^{2}} \mathrm{ds}\right)$ in addition to translational inertia $\left(\rho S \frac{\partial^{2} \mathrm{w}}{\partial \mathrm{t}^{2}} \mathrm{ds}\right)$.

Using Flügge's shell theory this leads to a modified shear force equation [8]:

$$
Q=\frac{\partial M}{\partial s}-\rho I \frac{\partial^{2}}{\partial t}\left(\frac{u}{R}+\phi\right)
$$

Substituting for the Flügge ${ }^{-}$based bending moment resultant, $M$, and the rotation of the normal to centre-line during deformation, $\phi$, gives the modified shear force resultant as:

$$
Q=-E I \frac{\partial}{\partial s}\left(\frac{w}{R^{2}}+\frac{\partial^{2} w}{\partial s^{2}}\right)-\rho I \frac{\partial^{2}}{\partial t^{2}}\left(\frac{2 u}{R}-\frac{\partial w}{\partial s}\right)
$$

A set of equations of motion for a curved beam which include the effect of rotary inertia are presented in [8]. These equations are listed in Table 3 in terms of the that

$L \quad$ circumferential distance parameter, s. Assuming/harmonic wave motion for the propagating waves is given by equation (4) and (5), the harmonic form of the equations of motion is given in Table 4.

By inspection of the resultant force expressions listed in Table 2 it can be seen that the bending moment and circumferential force expressions, when 
,L including rotary inertia effects, are identical to the corresponding Flügge jbased expressions. However, the shear force component now contains an additional rotary inertia term. Substituting the new shear force resultant, equation (41), into equation (A15) gives the shear force component of power transmission in the circumferential direction:

$$
P_{s f}=\left[\begin{array}{cc}
\left.E I \frac{\partial}{\partial s}\left(\frac{w}{R^{2}}+\frac{\partial^{2} w}{\partial s^{2}}\right)+\rho I \frac{\partial^{2}}{\partial t^{2}}\left(\frac{2 u}{R}-\frac{\partial w}{\partial s}\right)\right] & \frac{\partial w}{\partial t} . \text { shear force) } \\
\text { (radial velocity) }
\end{array}\right.
$$

For sinusoidal motion represented by equations (17) and (18) this becomes:

$$
\begin{aligned}
& P_{s f}=E I k_{A} A^{2} \omega\left(k_{A}{ }^{2}-\frac{1}{R^{2}}\right) \widehat{\sin ^{2}}\left[\omega t-k_{A} s+\theta_{A}\right] \\
& +\rho I\left(\frac{2}{R} B A \omega^{3}(\cos )\left[\omega t-k_{B} s\right] \overparen{\sin }\left[\omega t-k_{A} s+\theta_{A}\right]\right. \\
& \left.-k_{A} A^{2} \omega^{3} \widehat{(\sin 2}\left[\omega t-k_{A} s+\theta_{A}\right]\right) \text {. }
\end{aligned}
$$

The time-averaged shear force component is found by substituting equation (43) into equation (25) to give:

$$
\begin{gathered}
<\mathrm{P}_{\mathrm{sP}}>_{t}=\frac{E I k_{A} A^{2} \omega}{2}\left(k_{A}^{2}-\frac{1}{R^{2}}\right) \\
+\frac{\rho I \omega^{3}}{2}\left(\frac{2}{R} B A\left(\sin \left[k_{B} s-k_{A} s+\theta_{A}\right]-k_{A} A^{2}\right) .\right.
\end{gathered}
$$

For a single harmonic wave the shear force component becomes:

$$
\begin{gathered}
<\mathrm{P}_{\mathrm{sP}} \mathrm{P}_{\mathrm{t}}=\frac{\mathrm{EI} \mathrm{kA}^{2} \omega}{2}\left(\mathrm{k}^{2}-\frac{1}{\mathrm{R}^{2}}\right)-\frac{\rho \mathrm{I} \omega^{3} k \mathrm{~A}^{2}}{2} \\
+\frac{\rho \mathrm{I} \omega^{3} \mathrm{BA}}{\mathrm{R}}\left(\operatorname{Sin}\left[\theta_{\mathrm{A}}\right] .\right.
\end{gathered}
$$


The total power transmitted by a single elastic wave in the circumferential direction is given by the sum of the modified shear force component, equation (45), the previously derived bending moment component, equation (36), and extensional component, equation (35).

\subsection{THE EFFECT OF SHEAR DEFORMATION}

If shear deformation is included then Kirchoff's hypothesis (normals remain normal) is no longer valid, and the rotation of the normal to the centreline during bending, $\phi$, is no longer defined by equation (2) but is now another independent variable related to the shear angle, $\gamma$. Due to shear, a rectangular element of the beam tends to go into a diamond shape without rotation of the face, and the slope of the centre-line is diminished by the shear angle $\gamma$ :

$$
\left(\frac{\mathrm{u}}{\mathrm{R}}-\frac{\partial \mathrm{w}}{\partial \mathrm{s}}\right)=\phi-\gamma
$$

Figure 7 illustrates the shear deformation of a rectangular element.

The circumferential strain-displacement expressions are identical to those of

$L$ the simple bending theories. However, unlike the other theories considered, the substitution for the rotation, $\phi$, is omitted, Giving the circumferential straindisplacement in terms of tangential, $u$, radial, $w$, and rotational, $\phi$, displacements:

$$
e_{s}=\frac{1}{\left(1+\frac{z}{R}\right)}\left[\left(\frac{w}{R}+\frac{\partial u}{\partial s}\right)+z \frac{\partial \phi}{\partial s}\right]
$$

Substituting this equation into the circumferential stress-strain relation, equation (7), the circumferential stress-displacement equation is obtained:

$$
\sigma_{\mathrm{s}}=\mathrm{E} \frac{1}{\left(1+\frac{\mathrm{z}}{\mathrm{R}}\right)}\left[\left(\frac{\mathrm{W}}{\mathrm{R}}+\frac{\partial \mathrm{u}}{\partial \mathrm{s}}\right)+\mathrm{z} \frac{\partial \phi}{\partial \mathrm{s}}\right]
$$


Unlike simple bending theories, where the transverse shear strain, $\gamma_{\mathrm{sr}}$ is negligible, the transverse shear strain is now related to the shear angle, $\gamma$ :

$$
\gamma_{\mathrm{sr}}=\frac{\gamma}{\left(1+\frac{z}{\mathrm{R}}\right)}
$$

Using equation (46) this can be expressed in terms of displacements $\mathrm{u}, \mathrm{w}$ and $\phi$ :

$$
\gamma_{\mathrm{sr}}=\frac{1}{\left(1+\frac{\mathrm{z}}{\mathrm{R}}\right)}\left[\phi-\left(\frac{\mathrm{u}}{\mathrm{R}}-\frac{\partial \mathrm{w}}{\partial \mathrm{s}}\right)\right] .
$$

Substituting this into the shear stress-strain expression gives the shear stressdisplacement equation:

$$
\sigma_{\mathrm{sr}}=G \frac{1}{\left(1+\frac{Z}{R}\right)}\left[\phi-\left(\frac{\mathrm{u}}{\mathrm{R}}-\frac{\partial \mathrm{w}}{\partial \mathrm{s}}\right)\right] .
$$

By integrating the stresses across the beam thickness, the circumferential force, bending moment, and shear force resultant are obtained [8]:

$$
\begin{gathered}
N=E S\left(\frac{w}{R}+\frac{\partial u}{\partial s}\right)+\frac{E I}{R}\left(\frac{w}{R^{2}}+\frac{1}{R} \frac{\partial u}{\partial s}-\frac{\partial \phi}{\partial s}\right), \\
M=-E I\left(\frac{w}{R^{2}}+\frac{1}{R} \frac{\partial u}{\partial s}-\frac{\partial \phi}{\partial s}\right), \\
Q=\kappa G\left(S+\frac{I}{R^{2}}\right)\left[\phi-\left(\frac{u}{R}-\frac{\partial \omega}{\partial s}\right)\right],
\end{gathered}
$$

where $\kappa$ is the Timoshenko shear coefficient, whose value depends upon the shape of the cross-section.

A set of equations of motion for a curved beam which includes the effect of refepuce shear deformation is presented in ${ }^{\prime}[8]$. These equations are listed in Table 3 in 
terms of the circumferential distance parameter, s. For sinusoidal motion assume that the tangential and radial displacements are given as before by equations (4) and (5). In addition, let the rotation of the normal to the centre-line be defined by:

$$
\phi(s, t)=\tilde{\mathrm{C}} \exp [(\mathrm{i})(\omega \mathrm{t}-\mathrm{ks})],
$$

where $\tilde{C}$ is the complex wave amplitude. Substituting the harmonic displacement expressions (4), (5) and (55) into the shear deformation based equations of motion gives the harmonic form of the equations of motion which are listed in Table 4.

Power transmission equations in the circumferential direction can be obtained in a manner analogous to that given in Appendix A for the Love $\bar{L}^{-}$and Flügge based theories. First, consider the circumferential stress contribution equation (A3). Substituting the circumferential stress-displacement equation, (48), and the tangential displacement, equation (1a), into equation (A3) gives the power transmission due to circumferential stress:

$$
P_{s 1}=-\int_{-h / 2}^{h / 2} E \frac{1}{\left(1+\frac{z}{R}\right)}\left[\left(\frac{W}{R}+\frac{\partial u}{\partial s}\right)+z \frac{\partial \phi}{\partial s}\right]\left[\frac{\partial}{\partial t}(u+z \phi)\right] \text { dz. }
$$

The integrands are expanded, and terms of degree greater than three discarded. The integration is performed using the results of equations (A7a) - (A7d) to give the power transmission contribution due to circumferential stress, which as before can be identified as consisting of extensional, $\mathrm{P}_{\mathrm{e}^{\prime}}$ and bending moment, $\mathrm{P}_{\mathrm{m}^{\prime}}$ components:

$$
\begin{aligned}
& P_{e}=-\left[E S\left(\frac{W}{R}+\frac{\partial u}{\partial s}\right)+\frac{E I}{R}\left(\frac{W}{R^{2}}+\frac{1}{R} \frac{\partial u}{\partial s}-\frac{\partial \phi}{\partial s}\right)\right] \quad \frac{\partial u}{\partial t}, \\
& \left(\begin{array}{c}
\text { circumferential } \\
\text { force }
\end{array}\right) \quad\left(\begin{array}{c}
\text { circumferential } \\
\text { velocity }
\end{array}\right)
\end{aligned}
$$




$$
\begin{aligned}
& P_{b m}=E I\left[\frac{w}{R^{2}}+\frac{1}{R} \frac{\partial u}{\partial s}-\frac{\partial \phi}{\partial s}\right] \quad \frac{\partial \phi}{\partial t} . \\
& \left(\begin{array}{c}
\text { - bending } \\
\text { moment }
\end{array}\right) \quad\left(\begin{array}{c}
\text { rotational } \\
\text { velocity }
\end{array}\right)
\end{aligned}
$$

The contribution to the power transmission from the transverse shear stress is obtained from the product of the shear force resultant, equation (54), and the radial velocity, equation (1b), which gives the shear force component of power transmission:

$$
\begin{array}{r}
P_{s f}=-\kappa G\left(S+\frac{I}{R^{2}}\right)\left[\phi-\left(\frac{\mathrm{u}}{R}-\frac{\partial w}{\partial s}\right)\right] \quad \frac{\partial \mathrm{w}}{\partial \mathrm{t}} . \\
(- \text { shear force) }
\end{array}
$$

Thus, the total power transmission in the circumferential direction is given by the sum of the extensional, bending moment and shear force components.

For sinusoidal wave motion assume that the tangential and radial displacements are defined, as before, by equations (17) and (18). In addition, let the rotation of the normal to the centre-line be defined by:

$$
\begin{gathered}
\phi(\mathrm{s}, \mathrm{t})=\operatorname{Re}\left\{\widetilde{\mathrm{C}}\left(\exp ^{\mathrm{exp}}\left[\left(\omega \mathrm{t}-\mathrm{k}_{\mathrm{C}} \mathrm{s}\right)\right]\right\}\right. \\
=\mathrm{C}\left(\cos \left[\omega \mathrm{t}-\mathrm{k}_{\mathrm{C}} \mathrm{s}+\theta_{\mathrm{C}}\right]\right.
\end{gathered}
$$

where $\theta_{C}$ is the relative phase angle between the rotational and extensional motions. Substituting the harmonic displacements, equations (17), (18) and (60) into the extensional, bending moment and shear force components derived above gives the power transmission due to harmonic wave motion:

$$
\begin{aligned}
P_{e}= & \frac{E B A \omega}{R}\left(s+\frac{I}{R^{2}}\right) \overparen{\cos }\left[\omega t-k_{A} s+\theta_{A}\right] \overparen{\sin }\left[\omega t-k_{B} s\right] \\
& -\frac{E I}{R} k_{C} B C \omega \sin \left[\omega t-k_{C} s+\theta_{C}\right] \overparen{\sin }\left[\omega t-k_{B} s\right]
\end{aligned}
$$




$$
\begin{aligned}
& +E k_{B} B^{2} \omega\left(S+\frac{I}{R^{2}}\right) \sin ^{2}\left[\omega t-k_{A} s\right] \\
& P_{b m}=E I[k_{C} C^{2} \omega \overbrace{}^{2}\left[\omega t-k_{C} s+\theta_{C}\right] \\
& -\frac{A C}{R^{2}} \omega \circlearrowleft 0\left[\omega t-k_{A} s+\theta_{A}\right] \overparen{\sin }\left[\omega t-k_{C} s+\theta_{C}\right] \\
& \left.-\frac{k_{B} B C}{R} \omega \sin \left[\omega t-k_{B} s\right] \sin \left[\omega t-k_{C} s+\theta_{C}\right]\right] \text {, } \\
& P_{s f}=\kappa G\left(S+\frac{I}{R^{2}}\right)\left[\begin{array}{ll}
k_{A} & A^{2} \omega \sin ^{2}\left[\omega t-k_{A} s+\theta_{A}\right.
\end{array}\right] \\
& -\frac{B A \omega}{R} \circlearrowleft\left[\omega t-k_{A} s+\theta_{A}\right] \overparen{\cos }\left[\omega t-k_{B} s\right] \\
& +A C \omega \curvearrowleft\left[\omega t-k_{A} s+\theta_{A}\right]\left(\widehat{\cos }\left[\omega t-k_{C} s+\theta_{C}\right]\right] \text {. }
\end{aligned}
$$

Time-averaged power transmission due to sinusoidal wave motion is found by summing the harmonic power transmissions equations, (61) - (63), over one $2 / 9$ period using equation (25), $\stackrel{9}{9}$ iving the extensional, bending moment and shear force components, respectively:

$$
\begin{aligned}
& <\mathrm{P}_{\mathrm{e}}>_{\mathrm{t}}=\frac{\mathrm{EB} A \omega}{2 \mathrm{R}}\left(\mathrm{S}+\frac{\mathrm{I}}{\mathrm{R}^{2}}\right) \widehat{\operatorname{Sin}}\left[\mathrm{k}_{\mathrm{A}} \mathrm{s}-\mathrm{k}_{\mathrm{B}} \mathrm{s}-\theta_{\mathrm{A}}\right] \\
& -\frac{E I k_{C} C B \omega}{2 R} \curvearrowleft\left[k_{B} s-k_{C} s+\theta_{C}\right] \\
& +\frac{E k_{B} B^{2} \omega}{2}\left(S+\frac{I}{R^{2}}\right)
\end{aligned}
$$




$$
\begin{aligned}
<P_{b m}>_{t}=E I & {\left[\frac{k_{C} C^{2} \omega}{2}-\frac{A C \omega}{2 R^{2}} \sin \left[k_{A} s-k_{C} s-\theta_{A}+\theta_{C}\right]\right.} \\
& -\frac{k_{B} B C \omega}{2 R}\left(\cos \left[k_{C} s-k_{B} s-\theta_{C}\right]\right], \\
<P_{s f}>_{t}=\kappa G\left(s+\frac{I}{R^{2}}\right)\left[\frac{k_{A} A^{2} \omega}{2}-\frac{B A \omega}{2 R}\left(\sin \left[k_{B} s-k_{A} s+\theta_{A}\right]\right.\right. & \\
& \left.+\frac{A C \omega}{2} \sin \left[k_{C} s-k_{A} s+\theta_{A}-\theta_{C}\right]\right] .
\end{aligned}
$$

(66) For a single harmonic wave, equations (64) to become:

L

$$
\begin{aligned}
& <\mathrm{P}_{\mathrm{e}}>_{\mathrm{t}}=\frac{\mathrm{EkB} \mathrm{B}^{2} \omega}{2}\left(\mathrm{~S}+\frac{\mathrm{I}}{\mathrm{R}^{2}}\right)-\frac{\mathrm{EIkBC \omega}}{2 \mathrm{R}} \overparen{\cos }\left[\theta_{\mathrm{C}}\right] \\
& -\frac{E \omega B A}{2 R}\left(S+\frac{I}{R^{2}}\right) \sin \left[\theta_{A}\right] \\
& <\mathrm{P}_{\mathrm{bm}}>_{\mathrm{t}}=\frac{\mathrm{EI} \mathrm{kC^{2 } \omega}}{2}-\frac{\mathrm{EIkBC \omega}}{2 \mathrm{R}} \operatorname{Cos}\left[\theta_{\mathrm{C}}\right] \\
& -\frac{E I \omega A C}{2 R^{2}} \sin \left[\theta_{C}-\theta_{A}\right] \\
& \left\langle\mathrm{P}_{\mathrm{Sf}}\right\rangle_{t}=\kappa G\left(\mathrm{~S}+\frac{\mathrm{I}}{\mathrm{R}^{2}}\right)\left[\frac{\mathrm{kA} \mathrm{A}^{2} \omega}{2}-\frac{\omega \mathrm{BA}}{\mathrm{R}} \tilde{\sin }\left[\theta_{\mathrm{A}}\right]\right. \\
& +\frac{\omega A C}{2} \sin \left[\theta_{A}-\theta_{C}\right]
\end{aligned}
$$


Thus, the total time-averaged power transmission by a single harmonic wave in the circumferential direction is given by the sum of the extensional, bending moment, and shear force components.

\subsection{RESULTS OF COMPUTER SIMULATION}

To investigate the effect of beam curvature upon wave motion the rotary inertia based, and shear deformation based equations of motion were

? $\bar{L}$ L programmed in the same manner as the Lovę and Flüggé based equations. The simulated beams studied had material properties and physical dimensions identical to those investigated in section two.

Solution of the rotary inertia equations of motion reveals that this assumption only makes a difference to the wave motion in a curved beam at high frequency (when the wave lengths approach the dimensions of the thickness of the beam). At lower frequencies both the predominantly flexural wave and the predominantly extensional wave behave as predicted by the Love $? \bar{l} \dot{L}$ and Flüggq based theories.

Solution of the shear deformation equations of motion for a curved beam show that three types of elastic wave exist: the predominantly flexural and predominantly extensional waves of simple bending theory and additionally a predominantly rotational wave related to the shear angle. The relationships between wave number and frequency for these three wave types are shown in Figure 8. The data are displayed using the same non-dimensional frequency range and non-dimensional wave number range as used in Figure 4 . It can be seen in Figure 8 that both the predominantly extensional wave and the predominantly rotational wave exhibit "cut-on" frequencies. As before, the predominantly extensional wave 'cuts-on' when $\Omega=1.0$, and for this particular beam the predominantly shear wave 'cuts-on' at $\Omega=20$. For a straight beam the shear wave "cut-on" frequency is given in [5] as $\frac{\omega \mathrm{K}}{c_{S}}=1$, where $c_{S}$ is the wave 
speed of shear waves in a straight beam, i.e. $c_{S}=\sqrt{\frac{\kappa G}{\rho}}$. For a curved beam the "cut$\angle 2$ on" frequency can be found, from the characteristic equation in [8], to be when

$$
\frac{\omega K}{c_{S}}=\left[\frac{\left(1+\frac{K^{2}}{R^{2}}\right)\left(1+\frac{3 K^{2}}{R^{2}}\right)}{\left(1-\frac{K^{2}}{R^{2}}\right)}\right]^{1 / 2} .
$$

Thus, for the thickness to radius of curvature ratios considered in this study the curved beam shear wave "cut-on" frequency is approximately the same value as for the straight beam. Below the shear wave cut-on frequency the relationship between wave number and frequency for the predominantly flexural wave and the predominantly extensional wave is the same as that predicted by the Love, and Flügge based theories. However, the predominantly flexural wave and the predominantly extensional wave will now contain three wave components representing the flexural, extensional and rotational motion.

To investigate the effects of shear deformation upon time-averaged power transmission the shear deformation based equations, (67) to (69), were programmed in MATLAB and the simulated beams chosen to have the same dimensions and material properties as in the earlier studies. Figure 9 shows the relationship between transmitted power ratio and frequency, shown using the same non-dimensional frequency range as Figure 6. For the predominantly flexural wave the time-averaged power ratio is calculated by dividing the power transmitted by a flexural wave as predicted by shear deformation based theory by

$\mathcal{L}$ the power transmitted by a flexural wave as predicted by the Love $[$ based theory. Thus:

$$
\frac{P_{s d}}{P_{1 v}}=\frac{(67)+(68)+(69)}{(32)+(33)+(34)}
$$

For the predominantly extensional wave the time-averaged power ratio is calculated by substituting wave amplitude, phase angles and wave numbers for 
the predominantly extensional wave into equation (71). Figure 9 shows this ratio, marked with 'o' symbols, plotted against non-dimensional frequency. It can be seen in Figure 9 that below the ring frequency, $\frac{\omega R}{c_{0}}=1$, this ratio is zero because there is no travelling extensional wave. Above the ring frequency but below the shear wave cut-on frequency, $\Omega=20$, this ratio is one, indicating that there is no difference between the shear deformation and Love L based theories. However, above the shear wave cut-on frequency this ratio diverges from unity, thus, indicating that higher order effects are important. Figure 9 also shows the transmitted power ratio of the predominantly flexural wave (marked with ' + ' symbols). It can be seen in Figure 9 that below the ring frequency this ratio is one, indicating that there is no difference between the shear deformation and Love $\mathcal{L}$ based theories. Above the ring frequency this ratio differs from unity, indicating that higher order effects are important. This is not surprising since an analysis of "corrected" bending waves in a straight beam [16] has shown that corrections for rotary inertia and shear deformation will have a $10 \%$ difference on the propagation velocity, and hence power flow, when the wavelength is less than six times the thickness of the beam. For the curved beam used in the current study this occurs when the non-dimensional frequency, $\Omega$, is greater than 3.2. Power is also transmitted by the predominantly rotational wave, however, this wave has a very high 'cut-on' frequency and is above the main frequency range of interest of this study. Hence, the power transmitted by this wave is not shown.

\subsection{SUMMARY AND DISCUSSION}

This paper has presented expressions for vibrational power transmission in a curved beam derived using four different theories. LQve's based equations include extension of the centre-line during bending motion, and were the first set of equations considered. Flügge [based equations also include centre-line extensions and were the second set of equations used. Corrections for rotary 
inertia and shear deformation produced the third and fourth sets of equations, respectively.

Using the governing equations for each theory, expressions have been derived for power transmission along a curved beam which are given in terms of the centre-line displacements. By analogy with power transmission in a straight beam these equations are expressed in terms of extensional, bending moment and shear force components. By assuming sinusoidal wave motion, expressions have been developed which relate the time-averaged power transmission to the amplitudes of the extensional, flexural and rotational displacements.

Expressions for structural intensity in other types of curved structure have already been published; Pavic [12] has derived expressions for an arbitrarily shaped thin shell presented in terms of generalised curvilinear co-ordinates. These can be reduced to equations applicable to a curved beam by assuming that displacements occur in one plane only and then converting to polar co-ordinates.

?. $\bar{L}$ With some manipulation, Love $\bar{L}$ based power transmission equations are obtained. Pavic has also derived expressions for structural intensity in a circular cylindrical shell [11], which can be reduced to equations applicable to a curved beam by assuming that there is no axial motion. With some rearrangement ? i Flügge based power transmission equations are obtained. For ease of reference the equations for displacement, strain - displacement, stress-strain, and force resultants for each theory are presented in Tables 1 and 2. The equations of motion and their harmonic form are presented in Tables 3 and 4, whilst the equations for power transmission and time-averaged power transmission are presented in Tables 5 and 6.

For each theory the effect of curvature upon wave motion and power transmission was investigated using beams with different degrees of curvature. From the results of this study vibrational power transmission in curved beams can be classified into three different frequency regions whose limits depend upon the type of wave considered.

For the predominantly extensional wave the frequency regions are:

(i) below the ring frequency, $\Omega=1$, where curvature effects are important; 
(ii) above the ring frequency but below the shear wave cut-on frequency, $\frac{\omega K}{c_{s}}$ $=1$, where the curved beam behaves essentially as a straight beam; and

(iii) above the shear wave cut-on frequency, where higher order effects are important.

For the predominantly flexural wave the frequency regions are:

(i) below the ring frequency, $\Omega=1$, where curvature effects are important;

(ii) above the ring frequency but below the frequency where the wavelength is less than six times the thickness of the beam. In this region the curved beam behaves essentially as a straight beam; and

(iii) above the frequency where the wavelength is less than six times the thickness of the beam. In this region higher order effects are important.

\section{ACKNOWLEDGËMENT}

The analytical work presented in this paper was carried out while both authors were at the Institute of Sound and Vibration Research, University of Southampton. The financial support of the Marine Technology Directorate Limited is gratefully acknowledged. 


\section{REFERENCES}

1. J.L. HORNER and R.G. WHITE 1991 Journal of Sound and Vibration 141, 87-103. Prediction of vibrational power transmission through bends and joints in beam-like structures.

2. A.E.H. LOVE 1940 A treatise on the mathematical theory of elasticity. NewYork : Dover Publications.

3. T.E. LANG 1962 Jet Propulsion Laboratory Technical Report 32-261. Vibration of thin circular rings, Parts I and II.

4. W. SOEDEL 1985 Vibrations of shells and plates. New York : Dekker Publications.

5. K.F. GRAFF 1975 Wave motion in elastic solids. Oxford : Clarenden Press.

6. L.L. PHILIPSON 1956 Journal of Applied Mechanics 23, 364-366. On the role of extension in the flexural vibrations of rings.

7. L.S.D. MORLEY 1961 Quarterly Journal of Mechanics and Applied Mathematics 14, 155-172. Elastic waves in a naturally curved rod.

8. K.F. GRAFF 1970 IEEE Transactions on Sonics and Ultrasonics, SU-17 (1), 16. Elastic wave propagation in a curved sonic transmission line.

9. S.J. WALSH and R.G. WHITE 1999 Journal of Sound and Vibration 221, 887902. Mobility of a semi-infinite curved beam with constant curvature.

10. A.W. LEISSA 1977 Vibrations of shells. NASA SP-288, Washington DC.

11. G. PAVIC 1990 Journal of Sound and Vibration 142, 293-310. Vibrational energy flow in elastic circular cylindrical shells.

12. G. PAVIC 1990 Proceedings of Third International Congress on Intensity Techniques 91-98 Senlis, France. Vibrational energy flow in thin-walled shells.

- 13. R.S. LANGLEY 1994 Journal of Sound and Vibration 169, 29-42. Wave motion and energy flow in cylindrical shells. 

14. A.J. ROMANO, P.B. ABRAHAM and E.G. WILLIAMS 1990 Journal of the Acoustical Society of America 87,1166-1175. A Poynting vector formulation for thin shells and plates, its application to structural intensity analysis and source localisation. Part I : Theory.

- 15. M. HECKL 1990 Proceedings of the Third International Congress on Intensity Techniques, 13-20. Senlis, France. Waves, Intensities and Powers in Structures.

16. L. CREMER, M. HECKL and E.E. UNGAR 1973 Structure-Borne Sound. Springer-Verlag, Berlin. 
APPENDIX A : DERIVATION OF POWER TRANSMISSION

EQUATIONS USING LOVE'S STRAIN-DISPLACEMENT EXPRESSION AND FLÜGGE'S STRAIN-DISPLACEMENT EXPRESSION

Intensity in the circumferential direction of a curved beam is given by:

$$
I_{s}=-\sigma_{s} \frac{\partial U}{\partial t}-\sigma_{s r} \frac{\partial W}{\partial t} .
$$

By integrating across the thickness, $h$, the power transmission per unit length is obtained:

$$
\begin{aligned}
P_{S} & =\int_{-h / 2}^{h / 2} I_{S} d_{z}, \\
& =\int_{-h / 2}^{h / 2}\left(-\sigma_{s} \frac{\partial U}{\partial t}-\sigma_{s r} \frac{\partial W}{\partial t}\right) d z .
\end{aligned}
$$

Consider first the contribution due to the circumferential stress term of equation (A2):

$$
P_{s 1}=-\int_{-h / 2}^{h / 2}\left(\sigma_{s} \frac{\partial U}{\partial t}\right) d z .
$$

Substituting Love's strain-displacement equation into the circumferential stressstrain equation gives the circumferential stress-displacement equation:

$$
\sigma_{\mathrm{s}}=\mathrm{E}\left[\left(\frac{\mathrm{w}}{\mathrm{R}}+\frac{\partial \mathrm{u}}{\partial \mathrm{s}}\right)+\mathrm{z} \frac{\partial}{\partial \mathrm{s}}\left(\frac{\mathrm{u}}{\mathrm{R}}-\frac{\partial \mathrm{w}}{\partial \mathrm{s}}\right)\right] .
$$


Representing circumferential displacements of the material point in terms of displacements at the centre-line, equations (1a) and (2), gives the circumferential velocity:

$$
\frac{\partial U}{\partial t}=\frac{\partial}{\partial t}\left(u+z\left(\frac{u}{R}-\frac{\partial w}{\partial s}\right)\right)
$$

Substituting the circumferential stress-displacement equation (A4) and the circumferential velocity, equation (A5), into equation (A3) gives the power transmission per unit length due to circumferential stress:

$$
\begin{aligned}
P_{s 1}= & -\int_{-h / 2}^{h / 2} E\left[\left(\frac{w}{R}+\frac{\partial u}{\partial s}\right)+z \frac{\partial}{\partial s}\left(\frac{u}{R}-\frac{\partial w}{\partial s}\right)\right] \\
& \times \frac{\partial}{\partial t}\left[u+z\left(\frac{u}{R}-\frac{\partial w}{\partial s}\right)\right] \text { dz. }
\end{aligned}
$$

By expanding the integrands and discarding terms of degree greater than three, the integrations can be carried out using the results:

$$
\begin{aligned}
& \int_{-h / 2}^{h / 2} d z=h, \\
& \int_{-h / 2}^{h / 2} 2 d z=0, \\
& \int_{-h / 2}^{h / 2} z^{2} d z=\frac{h^{3}}{12}, \\
& h / 2 \\
& \int_{-h / 2} z^{3} d d z=0 .
\end{aligned}
$$


Thus, for a curved beam of unit width, the power transmission per unit length due to circumferential stress is:

$$
\begin{gathered}
P_{s 1}=-E h\left(\frac{w}{R}+\frac{\partial u}{\partial s}\right) \frac{\partial u}{\partial t} \\
-\frac{E h^{3}}{12}\left[\frac{\partial}{\partial s}\left(\frac{u}{R}-\frac{\partial w}{\partial s}\right)\right]\left[\frac{\partial}{\partial t}\left(\frac{u}{R}-\frac{\partial w}{\partial s}\right)\right] .
\end{gathered}
$$

For a strip beam of width, $\mathrm{b}$, the cross-sectional area, $\mathrm{S}$, and the second moment of area, $\mathrm{I}$, can be introduced to give the total power transmitted by the beam. By analogy with power transmission in a straight beam an extensional and a bending moment component can be identified:

$$
\begin{aligned}
& P_{e}=-E S\left(\frac{w}{R}+\frac{\partial u}{\partial s}\right) \quad \frac{\partial u}{\partial t}, \\
& \left(\begin{array}{c}
\left.-\begin{array}{c}
\text { circumferential } \\
\text { force }
\end{array}\right)
\end{array}\right)\left(\begin{array}{c}
\text { circumferential } \\
\text { velocity }
\end{array}\right) \\
& P_{b m}=-E I\left[\frac{\partial}{\partial s}\left(\frac{u}{R}-\frac{\partial w}{\partial s}\right)\right] \quad\left[\frac{\partial}{\partial t}\left(\frac{u}{R}-\frac{\partial w}{\partial s}\right)\right] . \\
& \left(\begin{array}{c}
\text { - bending } \\
\text { moment }
\end{array}\right) \quad\left(\begin{array}{c}
\text { rotational } \\
\text { velocity }
\end{array}\right)
\end{aligned}
$$

Now consider the contribution to power transmission per unit length due to the transverse shear stress term in equation (A2):

$$
P_{s f}=-\int_{-h / 2}^{h / 2}\left(\sigma_{s r} \frac{\partial W}{\partial t}\right) d z .
$$

The radial displacement, $W$, does not vary across the thickness of the beam, thus from equation ( $1 \mathrm{~b})$ the radial velocity is:

$$
\frac{\partial W}{\partial t}=\frac{\partial w}{\partial t} .
$$


Substituting the radial velocity into equation (A11) gives the power transmission per unit length due to transverse shear stress:

$$
P_{s f}=-\left[\int_{-h / 2}^{h / 2} \sigma_{s r} \partial z\right] \frac{\partial w}{\partial t}
$$

Although the transverse shear stress, $\sigma_{\mathbf{s} r}$ is negligible, a non-vanishing shear resultant, Q, can be defined as the integral across the thickness of the shear stress:

$$
Q=\int_{-h / 2}^{h / 2} \sigma_{\mathrm{sr}} \mathrm{d} z .
$$

Thus, the power transmission due to transverse shear stress is:

$$
P_{s f}=-Q \frac{\partial w}{\partial t}
$$

Substituting the Love/based expression for the shear force resultant, Q, gives an expression which can be identified as the shear force component of the power transmission:

$$
\begin{aligned}
P_{\text {sf }}=-\operatorname{EI} & {\left[\frac{\partial^{2}}{\partial s^{2}}\left(\frac{u}{R}-\frac{\partial w}{\partial s}\right)\right] \quad \frac{\partial w}{\partial t} . } \\
& \text { (shear force) (radial velocity) }
\end{aligned}
$$

Thus, the total power transmission in the circumferential direction is given by the sum of the extensional, bending moment and shear force components:

$$
\mathrm{P}_{\mathrm{s}}=\mathrm{P}_{\mathrm{e}}+\mathrm{P}_{\mathrm{bm}}+\mathrm{P}_{\mathrm{sf}}
$$

To evaluate the power transmission using Flügge's strain-displacement expression, consider first the contribution due to the circumferential stress, equation (A3). Substituting Flügge's strain-displacement equation (3) into the 
circumferential stress-strain equation gives Flügge's stress-displacement equation:

$$
\sigma_{s}=E \frac{1}{\left(1+\frac{z}{R}\right)}\left[\left(\frac{w}{R}+\frac{\partial u}{\partial s}\right)+z \frac{\partial}{\partial s}\left(\frac{u}{R}-\frac{\partial w}{\partial s}\right)\right] .
$$

Substituting the circumferential stress equation (A18) and the circumferential velocity, equation (A5), into equation (A3) gives the power transmission per unit length due to circumferential stress:

$$
\begin{aligned}
P_{s 1}=-\int_{-h / 2}^{h / 2} E & \frac{1}{\left(1+\frac{z}{R}\right)}\left[\left(\frac{w}{R}+\frac{\partial u}{\partial s}\right)+z \frac{\partial}{\partial s}\left(\frac{u}{R}-\frac{\partial w}{\partial s}\right)\right] \\
& \times \frac{\partial}{\partial t}\left[u+z\left(\frac{u}{R}-\frac{\partial w}{\partial s}\right)\right] d z .
\end{aligned}
$$

For a curved beam, $\frac{z}{R}$ is less than unity, thus the quotient $\frac{1}{\left(1+\frac{z}{R}\right)}$ can be expanded as a geometric series:

$$
\frac{1}{\left(1+\frac{z}{R}\right)}=\sum_{n=0}^{\infty}\left(-\frac{z}{R}\right)^{n}
$$

For sufficiently small $\frac{\mathrm{Z}}{\mathrm{R}}$ this series can be truncated after terms of degree three. Substituting the truncated series into equation (A19), the integrands are expanded and terms of degree greater than three discarded. The integrations are then carried out using the results (A7a) - (A7d) to give power transmission due to circumferential stress in a curved beam of unit width as: 


$$
\begin{aligned}
P_{s 1}= & -E\left[h\left(\frac{w}{R}+\frac{\partial u}{\partial s}\right)+\frac{h^{3}}{12 R}\left(\frac{w}{R^{2}}+\frac{\partial^{2} w}{\partial s^{2}}\right)\right] \frac{\partial u}{\partial t} \\
& +\frac{E h^{3}}{12}\left[\frac{w}{R^{2}}+\frac{\partial^{2} w}{\partial s^{2}}\right]\left[\frac{\partial}{\partial t}\left(\frac{u}{R}-\frac{\partial w}{\partial s}\right)\right] .
\end{aligned}
$$

For a beam of width, $b$, an extensional and a bending moment component of energy flow can be identified:

$$
\begin{aligned}
& P_{e}=-\left[E S\left(\frac{w}{R}+\frac{\partial u}{\partial s}\right)+\frac{E I}{R}\left(\frac{w}{R^{2}}+\frac{\partial^{2} w}{\partial s^{2}}\right)\right] \quad \frac{\partial u}{\partial t}, \\
& \left(\begin{array}{c}
- \text { circumferential } \\
\text { force }
\end{array}\right) \quad\left(\begin{array}{c}
\text { circumferential } \\
\text { velocity }
\end{array}\right) \\
& P_{b m}=E I\left[\frac{w}{R^{2}}+\frac{\partial^{2} w}{\partial s^{2}}\right] \quad\left[\frac{\partial}{\partial t}\left(\frac{u}{R}-\frac{\partial w}{\partial s}\right)\right] . \\
& \left(\begin{array}{c}
\text { - bending } \\
\text { moment }
\end{array}\right) \quad\left(\begin{array}{c}
\text { rotational } \\
\text { velocity }
\end{array}\right)
\end{aligned}
$$

The contribution to power transmission due to transverse shear stress can be ? $[$ evaluated using equation (A15) and substituting the Flüggej based expression for shear force resultant, to give the shear force component of power transmission:

$$
\begin{aligned}
& P_{s f}=E I\left[\frac{\partial}{\partial s}\left(\frac{w}{R^{2}}+\frac{\partial^{2} w}{\partial s^{2}}\right)\right] \quad \frac{\partial w}{\partial t} . \\
& \left(\begin{array}{c}
- \text { shear } \\
\text { force }
\end{array}\right) \quad\left(\begin{array}{c}
\text { radial } \\
\text { velocity }
\end{array}\right)
\end{aligned}
$$

Thus, the total power transmission in the circumferential direction is given by the sum of the extensional, bending moment and shear force components. 


\section{APPENDIX B : NOTATION}
A flexural wave amplitude
$\mathrm{A}_{\mathrm{f}} \quad$ amplitude of flexural wave in a straight beam
B extensional wave amplitude
$\mathrm{B}_{\mathrm{ex}} \quad$ amplitude of extensional wave in a straight bar
C rotation wave amplitude
E Young's modulus
G shear modulus
I second moment of area of cross-section of beam
$\mathrm{I}_{\mathrm{S}} \quad$ structural intensity in circumferential direction
$\mathrm{K}$ radius of gyration
M. bending moment on cross-section of beam
$\mathrm{N} \quad$ circumferential force on cross-section of beam
$\mathrm{P} \quad$ transmitted power ${ }^{1}$
$\mathrm{P}_{\mathrm{bm}} \quad$ bending moment component of transmitted power
$\mathrm{P}_{\mathrm{e}} \quad$ extensional component of transmitted power
$P_{\text {ex }} \quad$ power transmitted by extensional wave in a straight bar
$\mathrm{P}_{\mathrm{f}} \quad$ power transmitted by flexural wave in a straight beam
$\mathrm{P}_{\mathrm{S}} \quad$ transmitted power in circumferential direction
$P_{\mathrm{s} 1} \quad$ transmitted power due to circumferential stress
$\mathrm{P}_{\mathrm{sf}} \quad$ shear force component of transmitted power
Q shear force on cross-section of beam
$\mathrm{R} \quad$ radius of curvature
S cross-sectional area of beam
T period of wave
$\mathrm{U}$ displacement of material point in circumferential direction
W displacement of material point in radial direction 


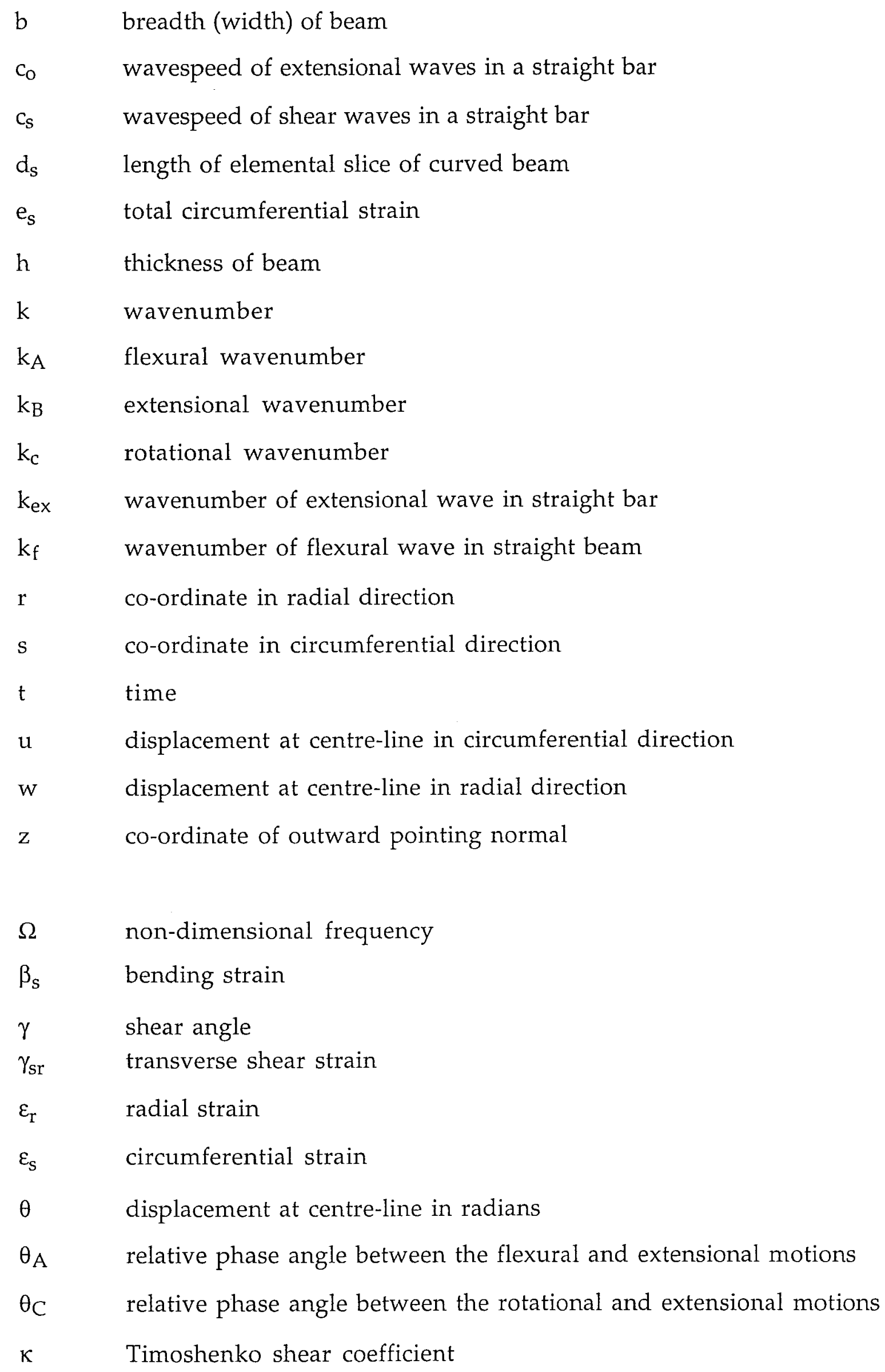




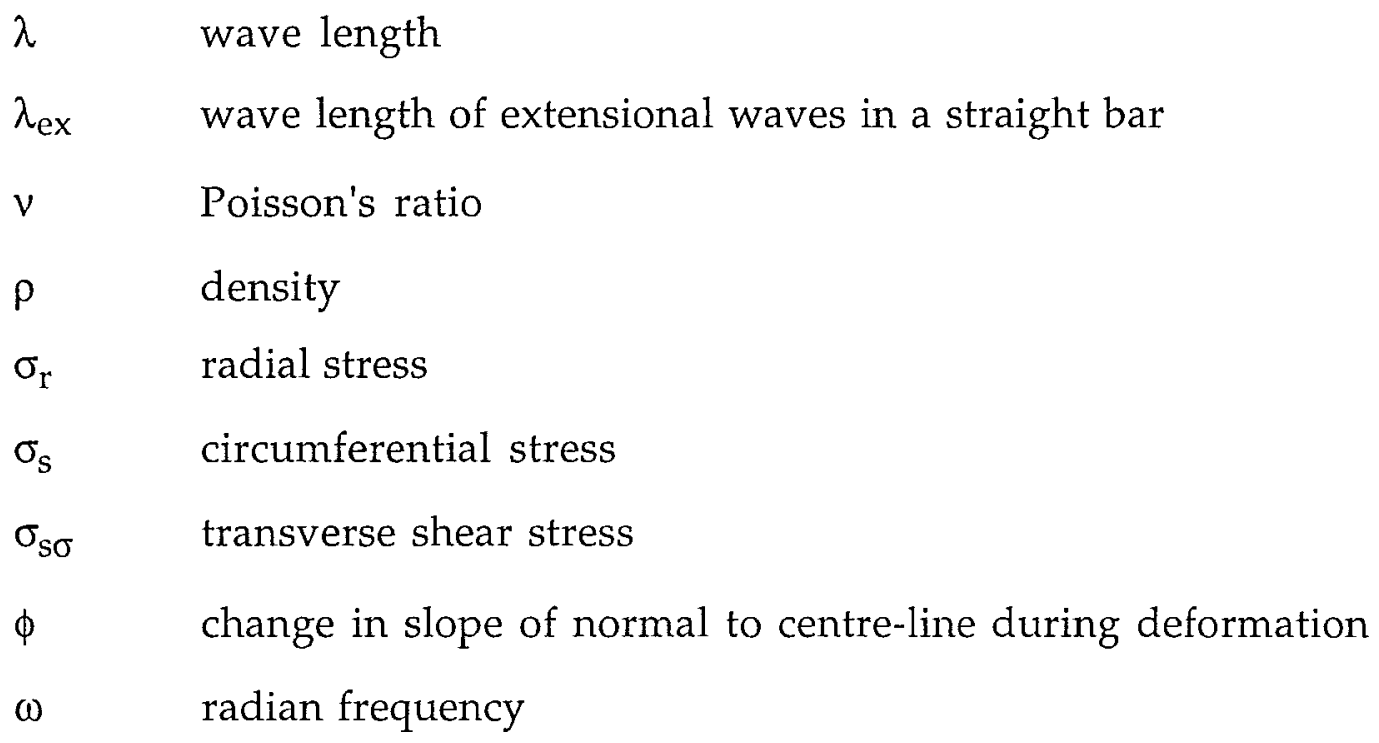

1 The term 'power flow', although not physically accurate, has gained widespread acceptance. In this paper the term 'transmitted power' is used to denote the power (in Watts) flowing through a beam, whilst the term 'intensity' is used to denote the power transmitted per unit area normal to the direction of propagation (in Watts $/ \mathrm{m}^{2}$ ). 


\section{LIST OF TABLES}

Table

1 Displacement, strain-displacement and stress-strain equations for a curved beam.

2 Force resultants for a curved beam.

3 Equations of motion for a curved beam.

4 Harmonic form of the equations of motion for a curved beam.

5 Power transmission equations for a curved beam.

6. Equations for time-averaged power transmission by a single harmonic wave. 


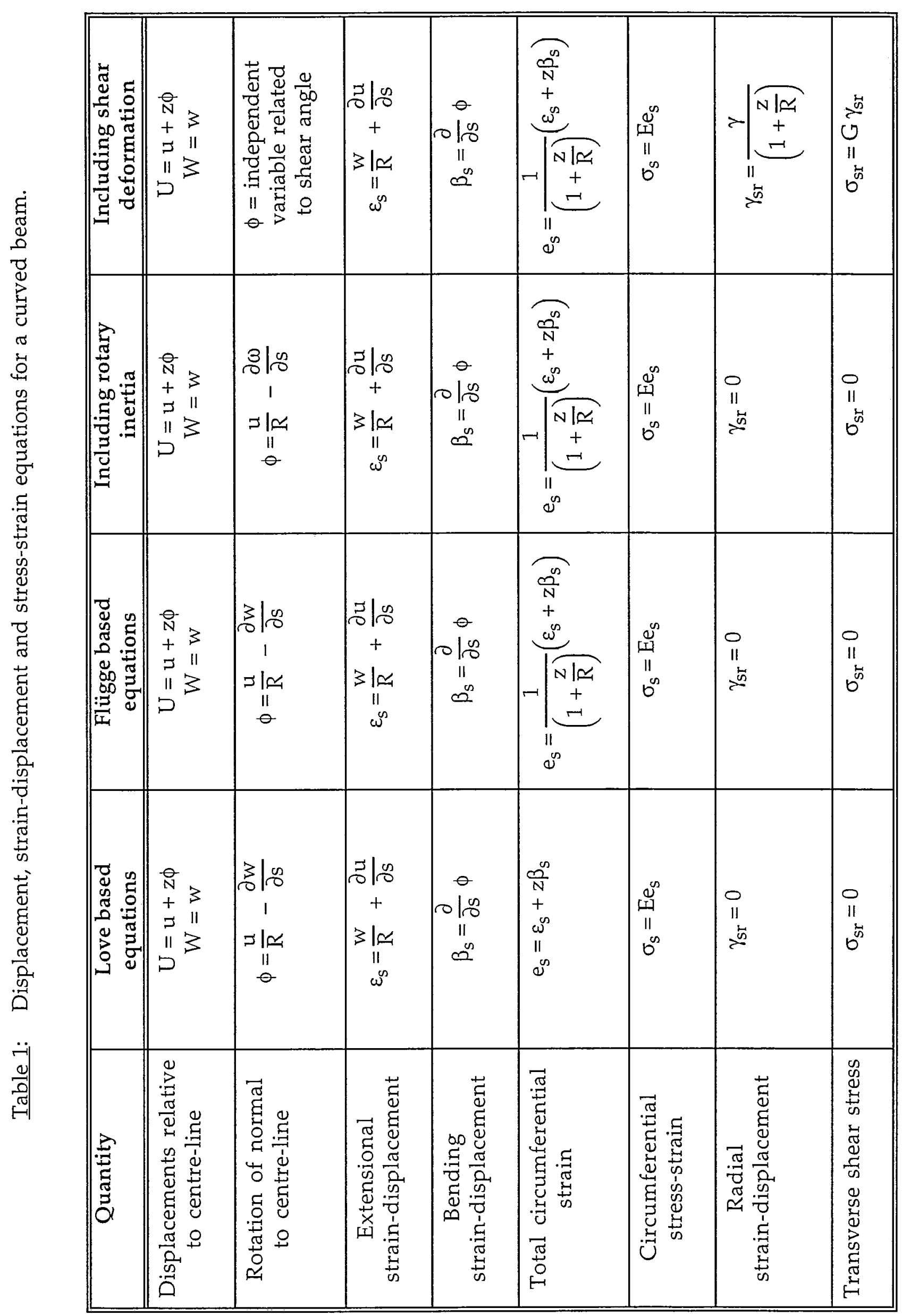




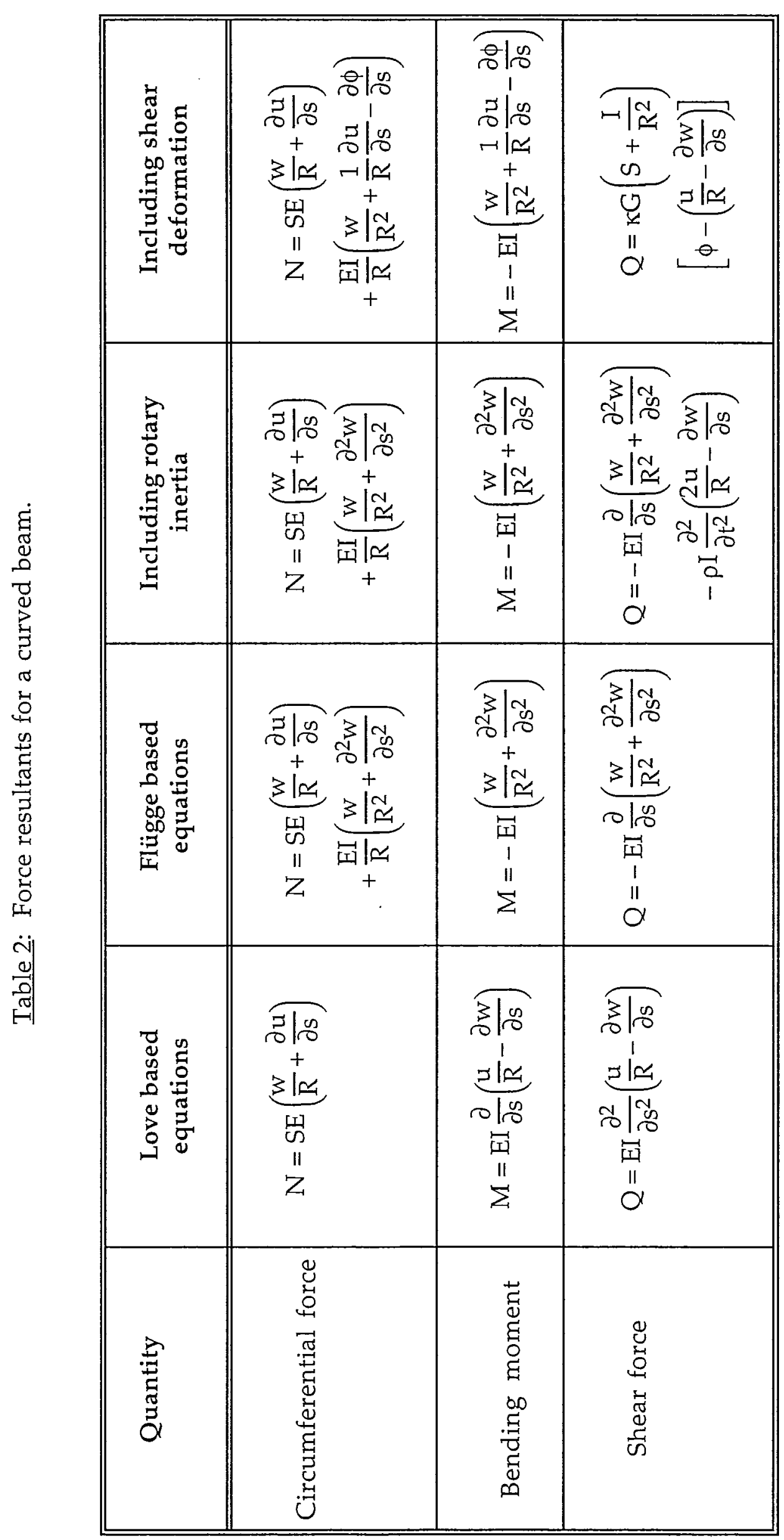




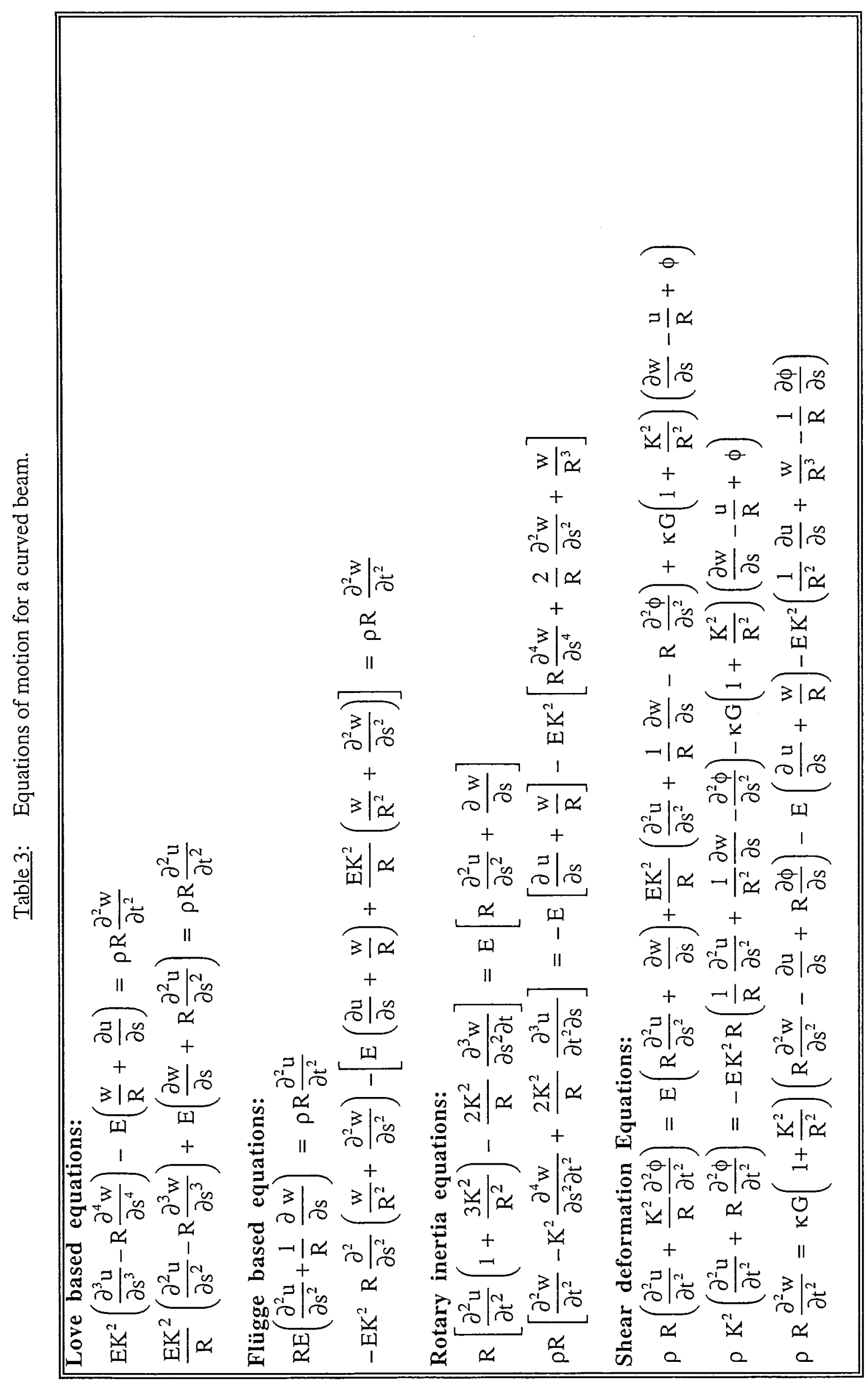




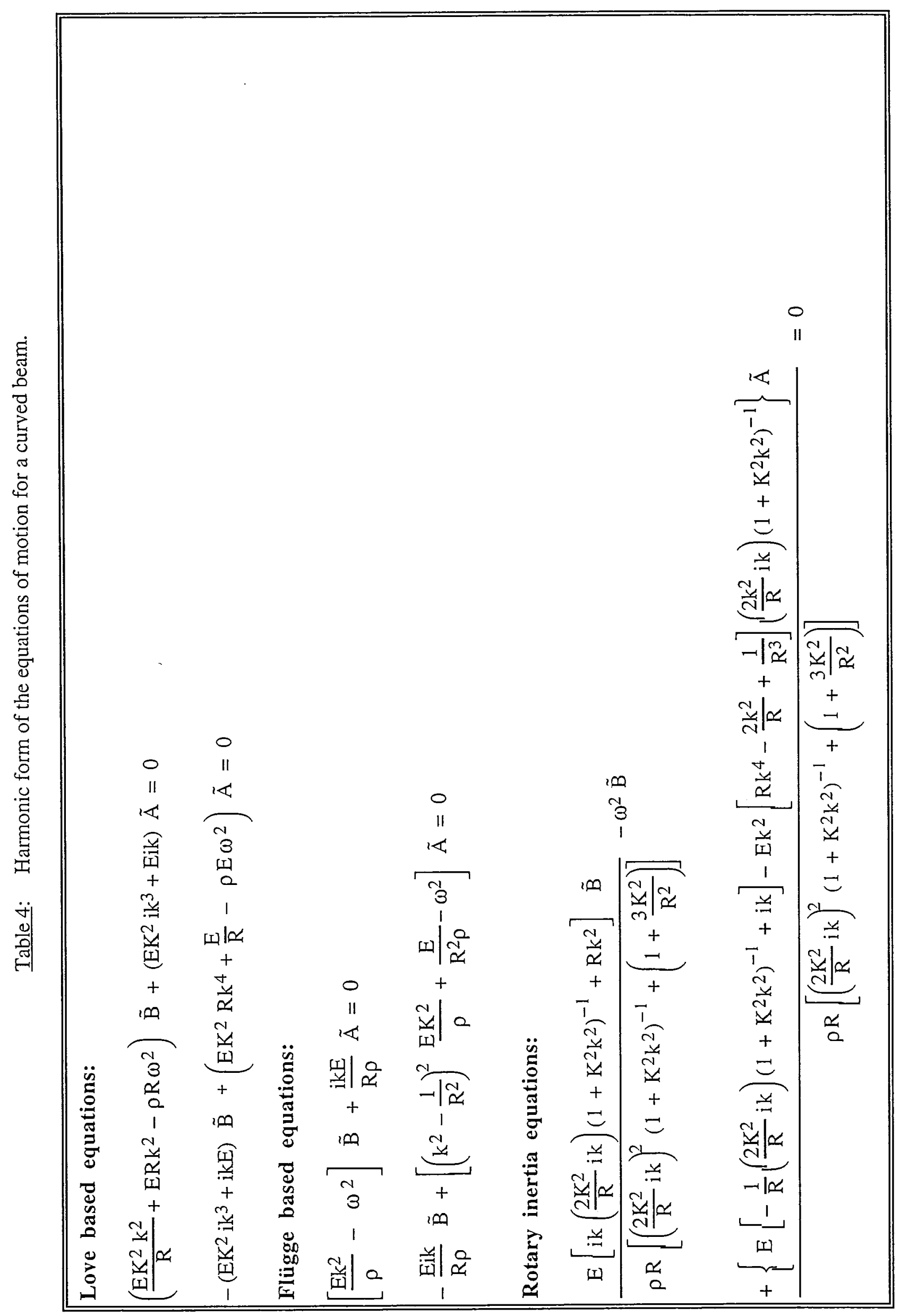




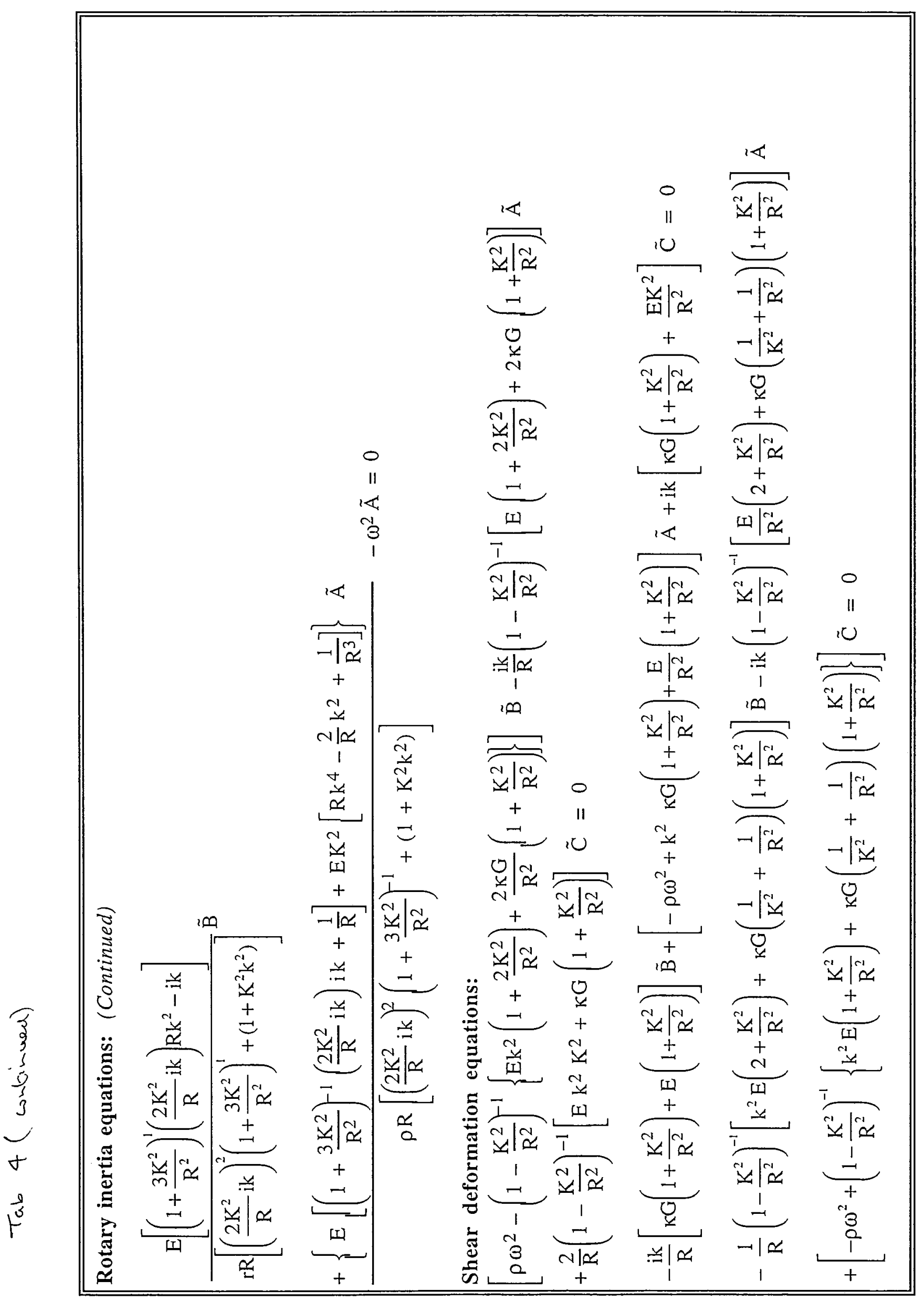




\begin{tabular}{|c|c|c|c|}
\hline 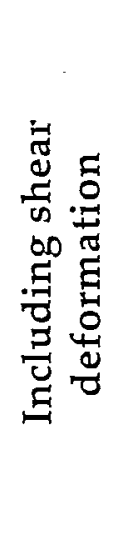 & 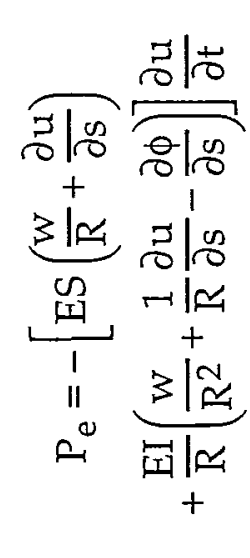 & 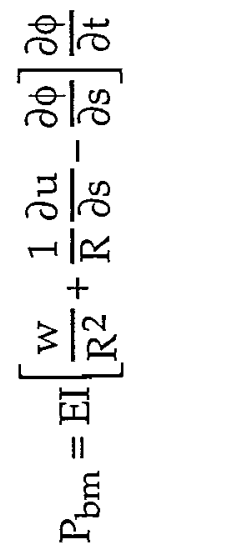 & 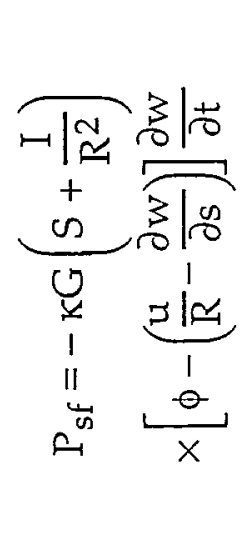 \\
\hline 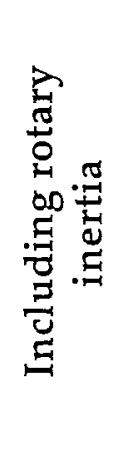 & 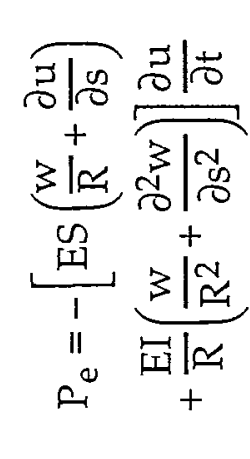 & 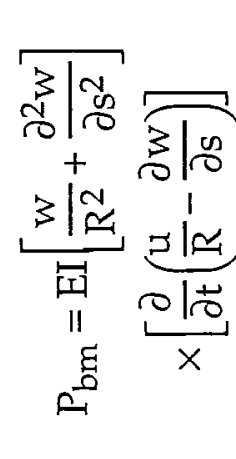 & 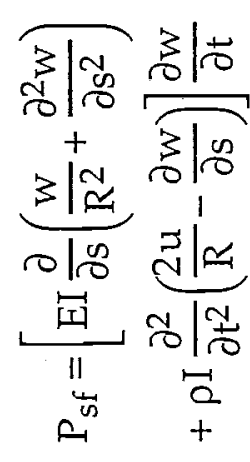 \\
\hline 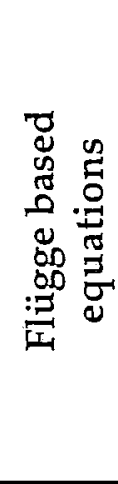 & 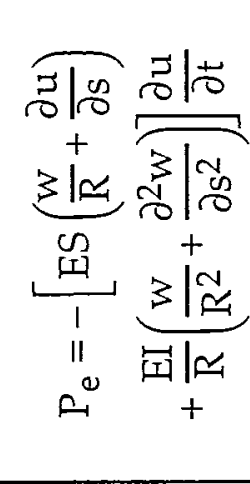 & 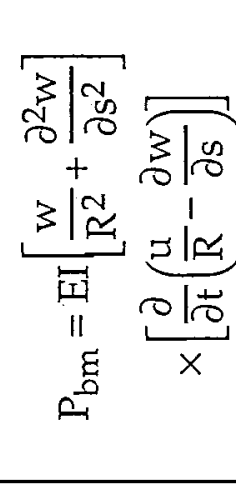 & 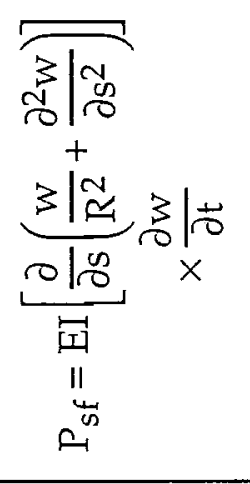 \\
\hline 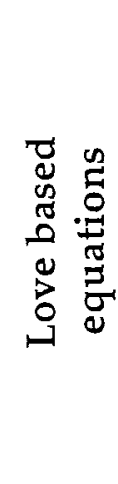 & 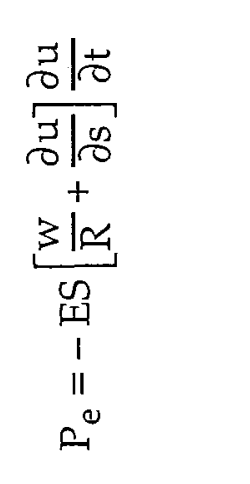 & 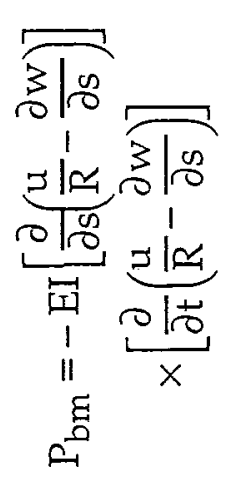 & 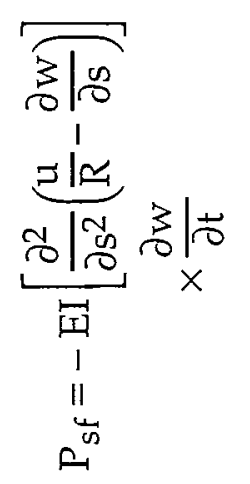 \\
\hline 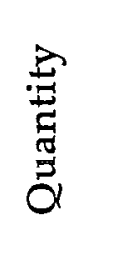 & 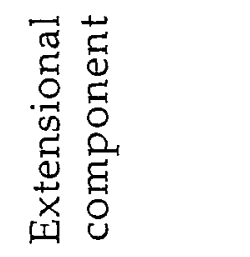 & 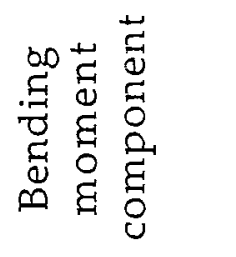 & 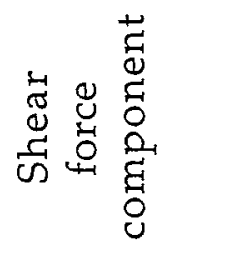 \\
\hline
\end{tabular}




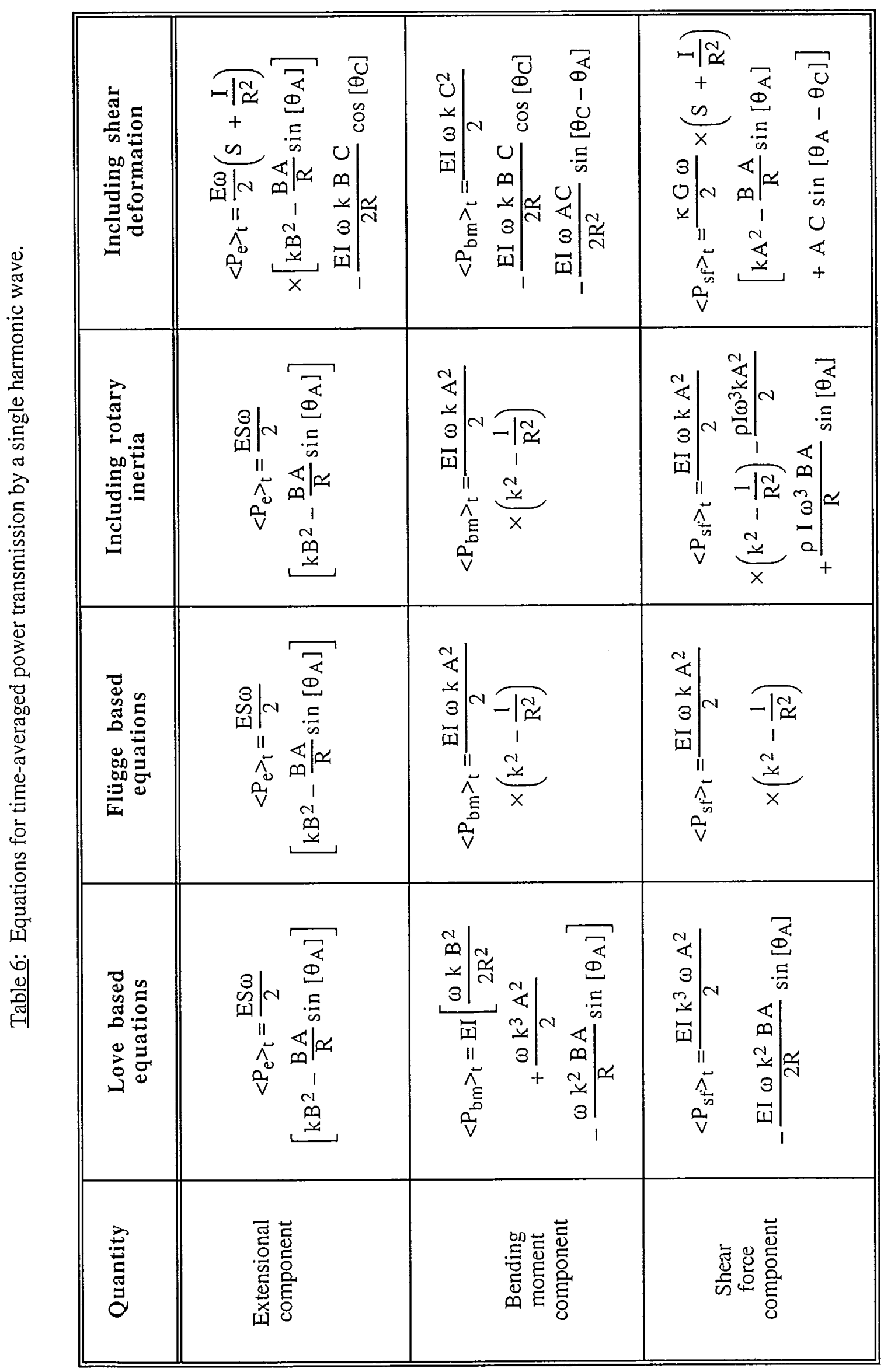




\section{FIGURE CAPTIONS}

Figure

1 A typical machinery installation in a ship.

2 Geometry of a curved beam.

3 Sign convention and force resultants on an elemental slice of curved beam.

4 Non-dimensional wave number, $k R$, versus non-dimensional frequency, $\Omega=\omega R / c_{0}$, relationship for a curved beam with a thickness to radius ratio of $(1 / 10)$ predicted using the Love based theory: ' + ' $=$ predominantly flexural travelling wave; ' $\mathrm{o}$ ' $=$ predominantly extensional travelling wave.

5 Wave amplitude ratio versus non-dimensional frequency, $\Omega=\omega \mathrm{R} / \mathrm{c}_{0}$, relationship for a curved beam with a thickness to radius ratio of $\left(1 /{ }_{10}\right)$ predicted using the Love based theory: ' $+{ }^{\prime}=$ wave amplitude ratio (extensional amplitude / flexural amplitude) for a predominantly flexural travelling wave; ' $\mathrm{O}$ ' = wave amplitude ratio (flexural amplitude / extensional amplitude) for a predominantly extensional travelling wave.

Transmitted power ratio versus non-dimensional frequency, $\Omega=\omega \mathrm{R} / \mathrm{c}_{0}$, relationship for a curved beam with a thickness to radius ratio of $\left(1 /{ }_{10}\right)$ predicted using the Love based theory: ' $+{ }^{\prime}=$ transmitted power ratio, $\left.(<\mathrm{P}\rangle /\left\langle\mathrm{P}_{\mathrm{f}}\right\rangle\right)$, for a predominantly flexural travelling wave; ' $\mathrm{o}$ ' = transmitted power ratio, $\left(<\mathrm{P}>/<\mathrm{P}_{\mathrm{ex}}>\right)$, for a predominantly extensional travelling wave. 
7 Shear deformation of a rectangular element: ' $\phi$ ' $=$ rotation of normal to centre line; ' $\gamma$ ' = shear angle.

8 Non-dimensional wave number, $k R$, versus non-dimensional frequency, $\Omega=\omega R / c_{0}$, relationship for a curved beam, with a thickness to radius ratio of $\left(1 /{ }_{10}\right)$ predicted using the shear deformation based theory: ${ }^{\prime}+=$ predominantly flexural travelling wave; ' $\mathrm{o}$ ' $=$ predominantly extensional travelling wave; ' $x$ ' = predominantly shear travelling wave.

9 Transmitted power ratio, $\left(\left\langle\mathrm{P}_{\mathrm{sd}}\right\rangle /\left\langle\mathrm{P}_{\mathrm{lv}}\right\rangle\right)$, versus non-dimensional frequency, $\Omega=\omega R / c_{0}$, relationship for a curved beam with a thickness to radius ratio of $\left({ }^{1} /{ }_{10}\right)$ predicted using the shear deformation and Love based theories: ' + ' $=$ transmitted power ratio for a predominantly flexural wave ratio; ' $\mathrm{o}$ ' $=$ transmitted power ratio for a predominantly extensional wave. 


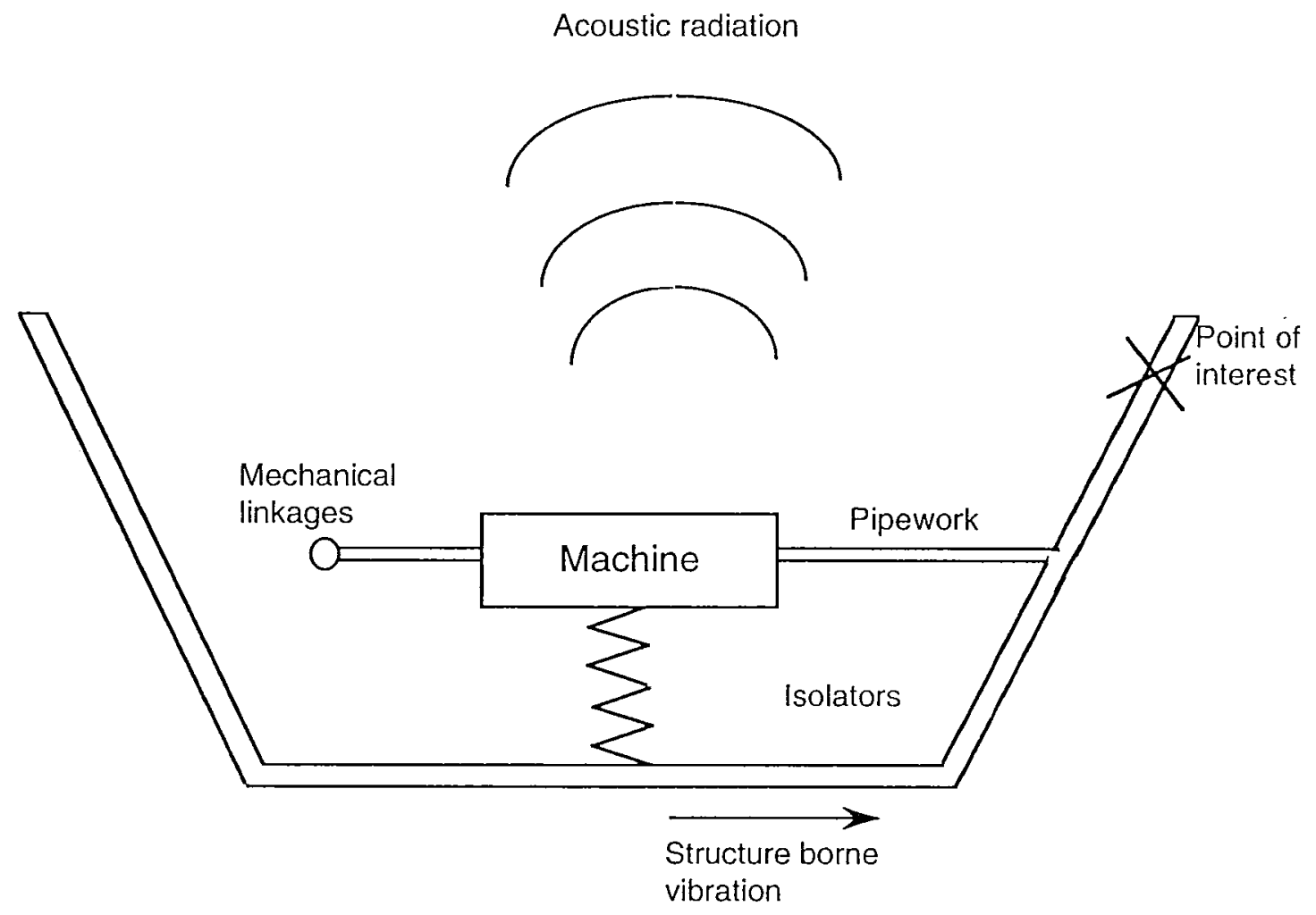


Fig 2

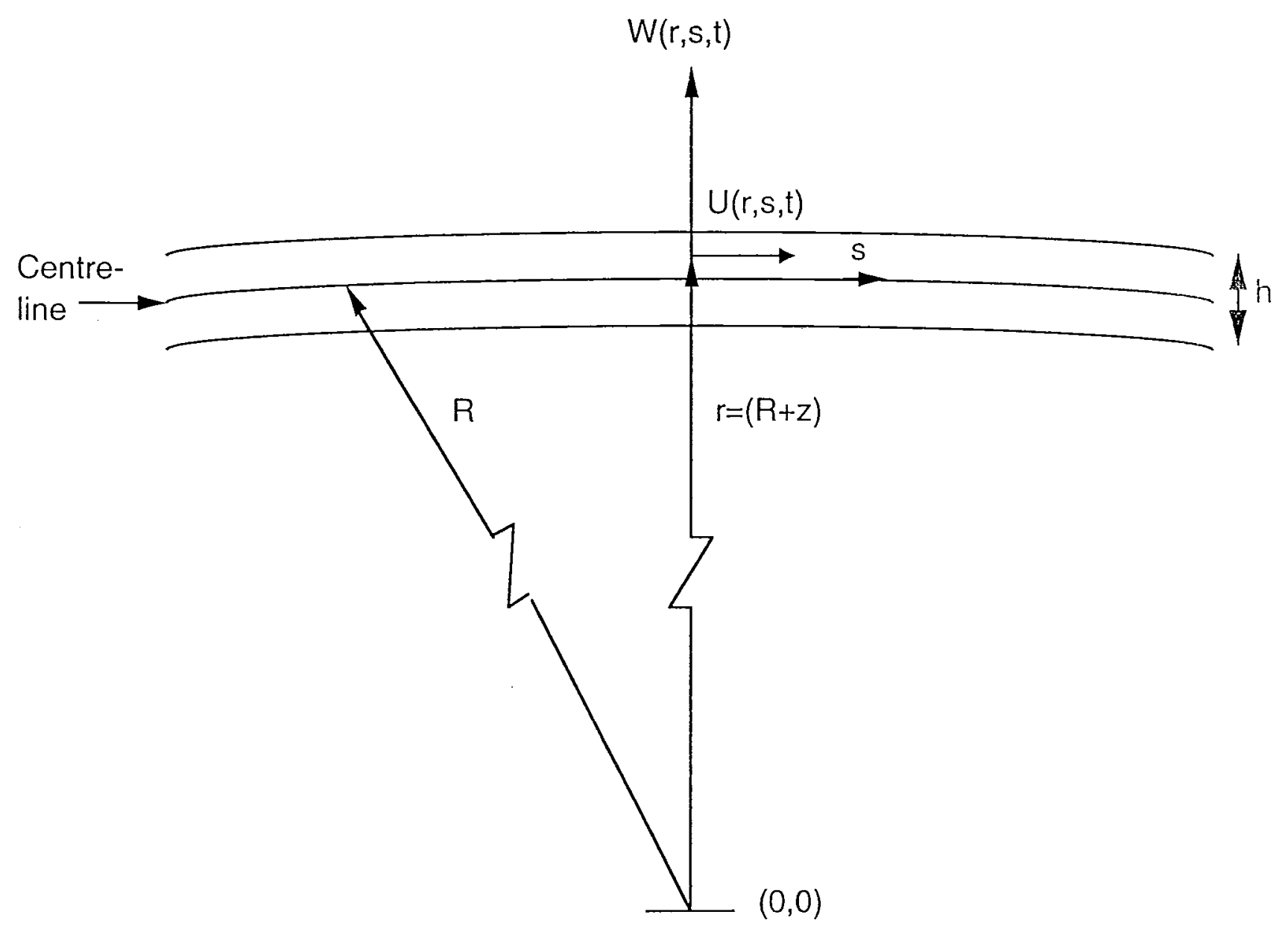


ds
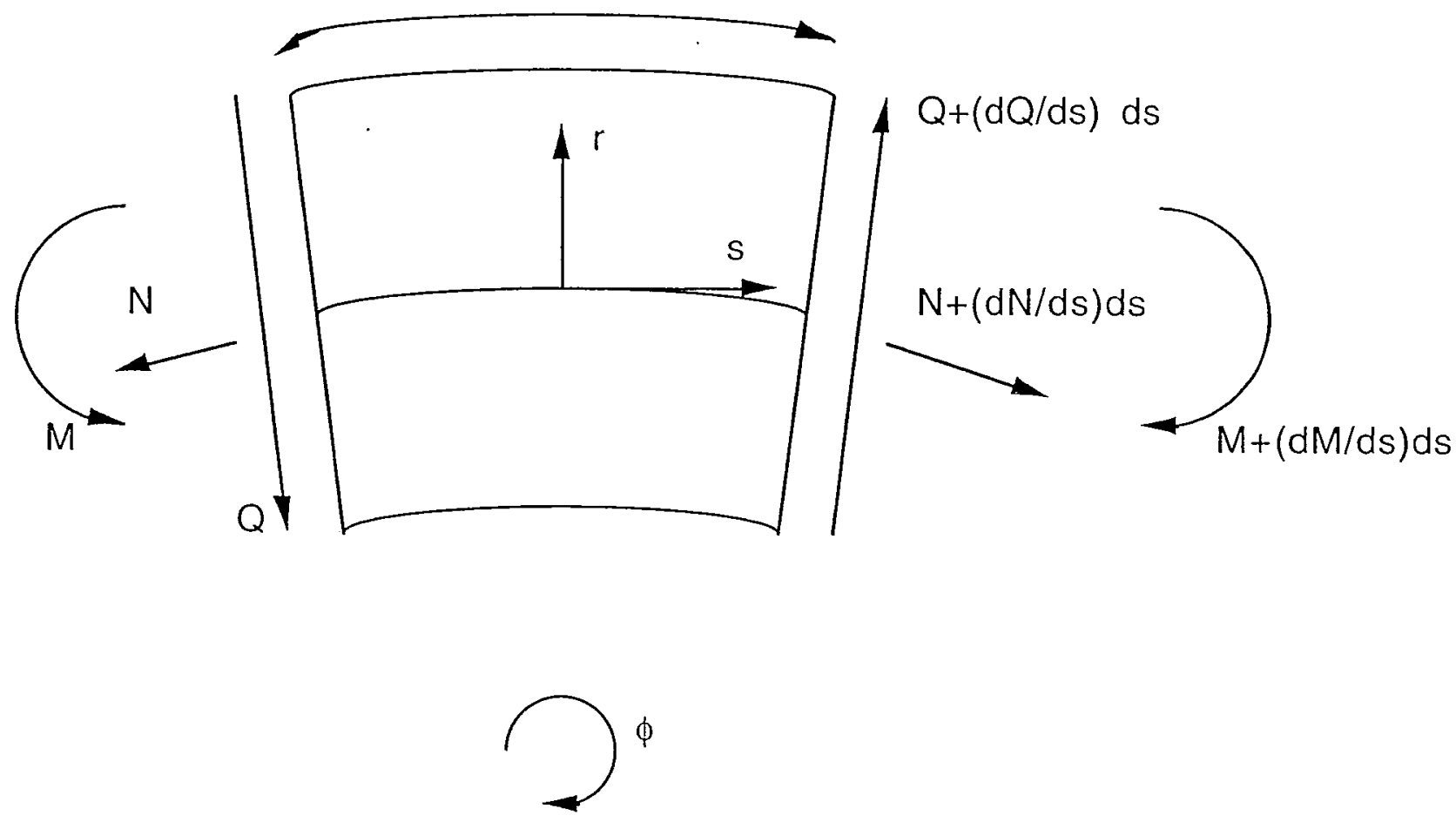


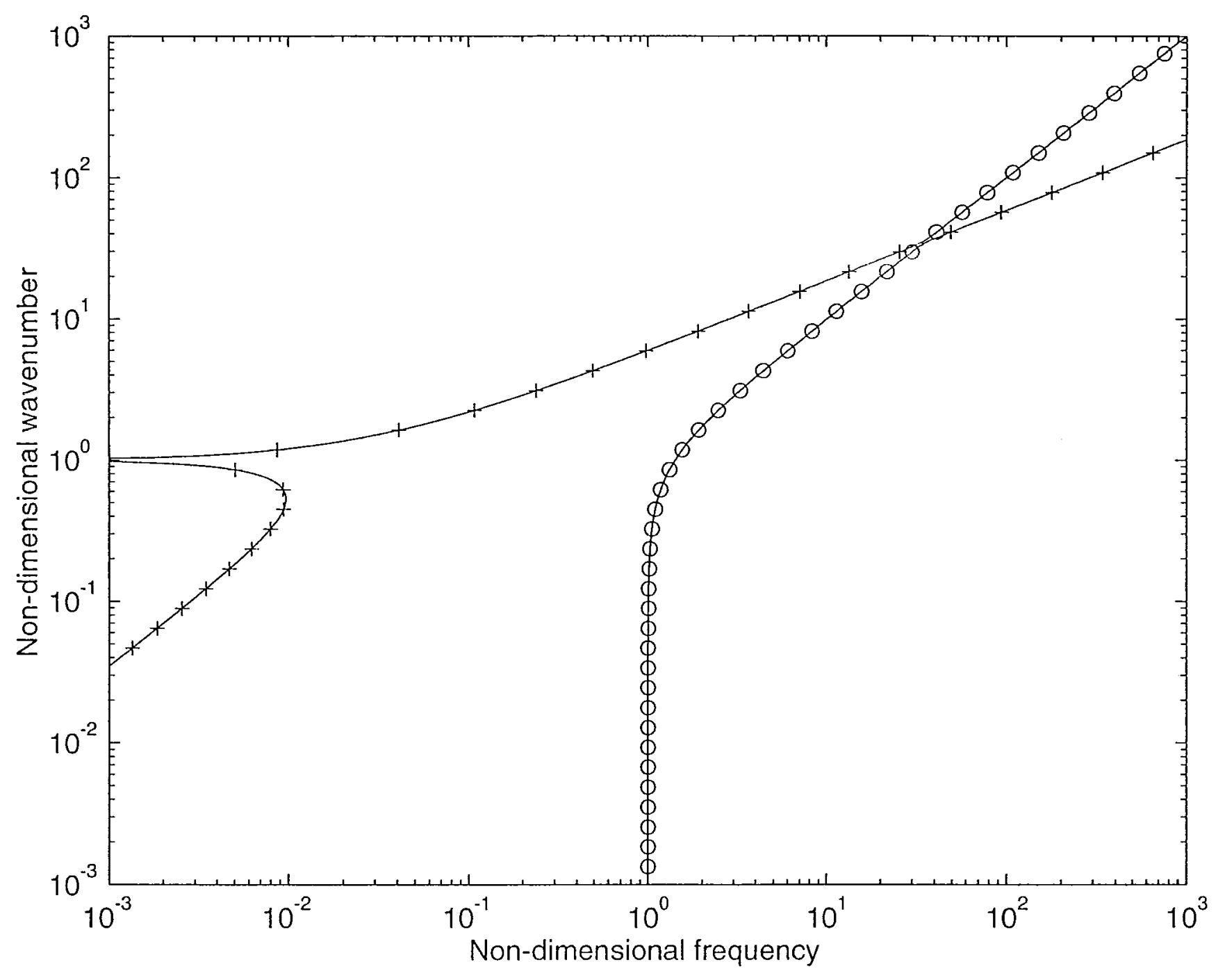




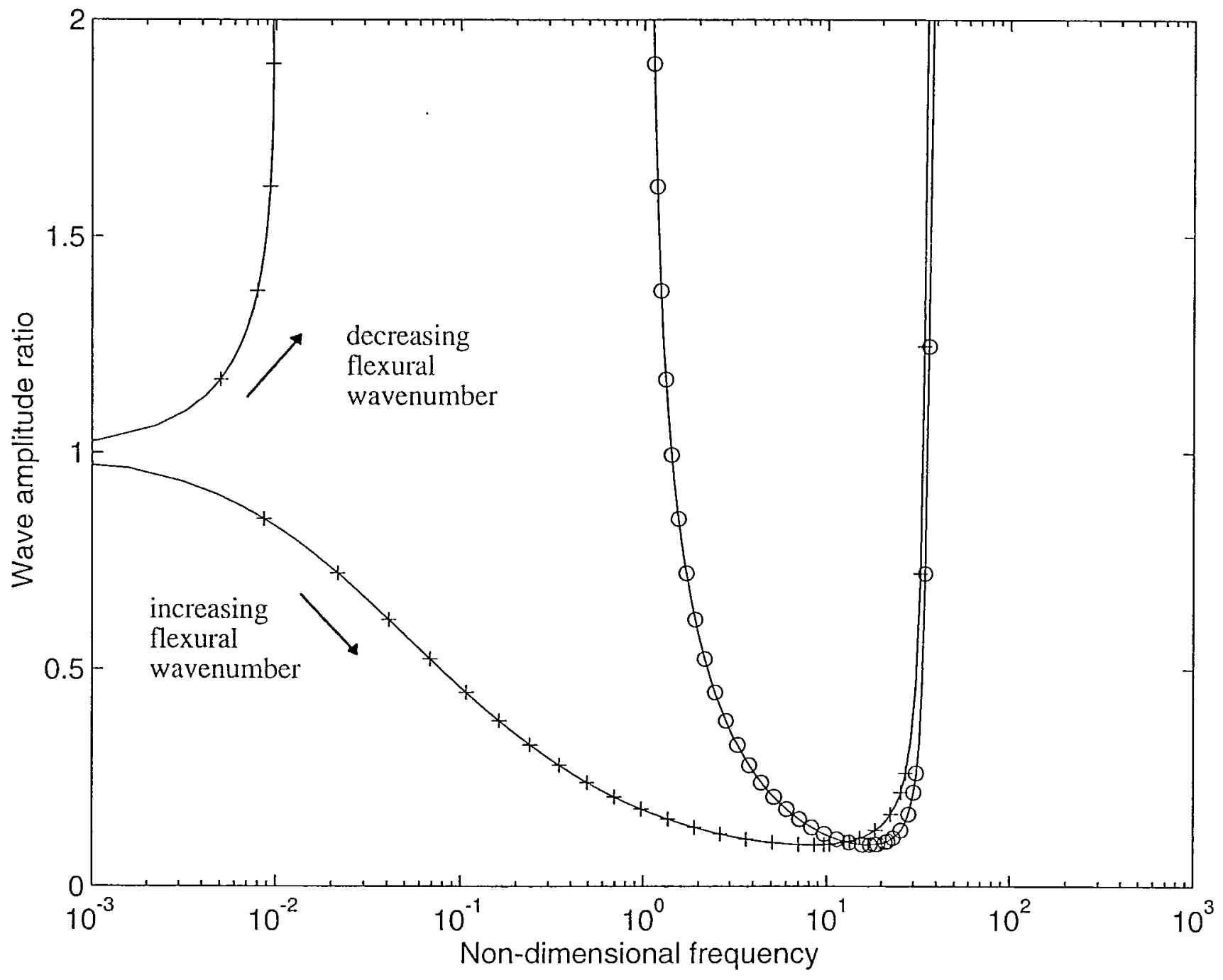




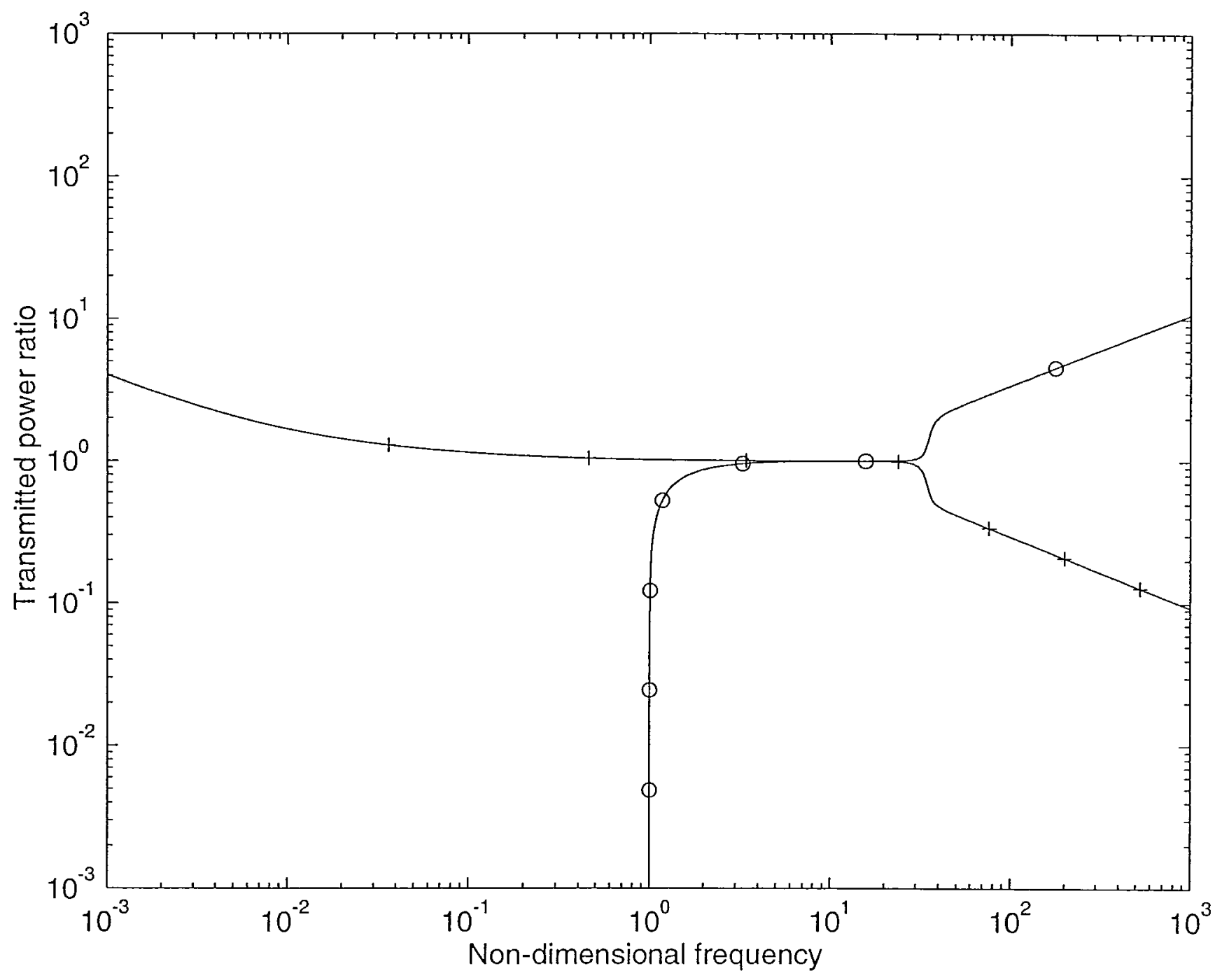




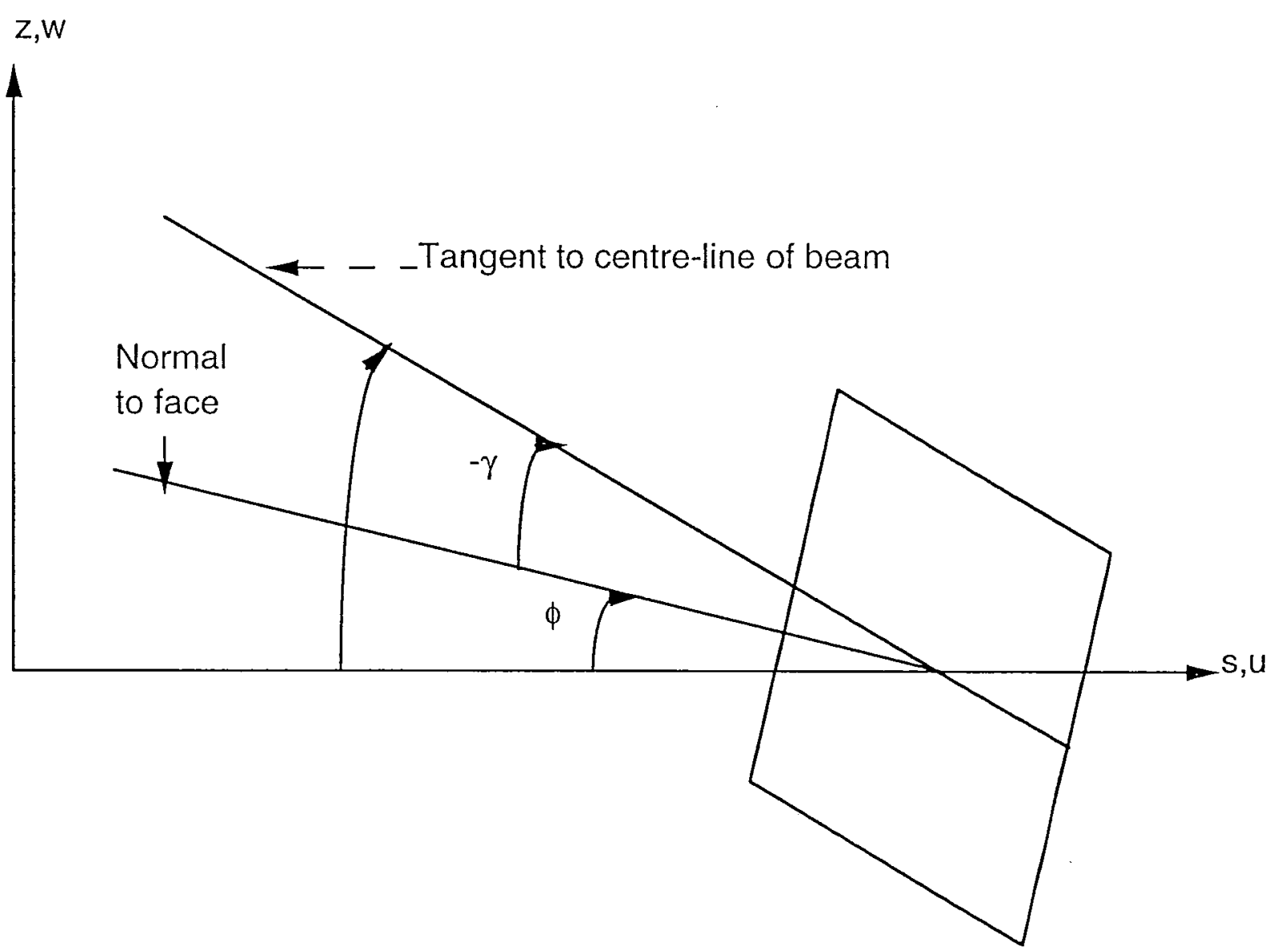




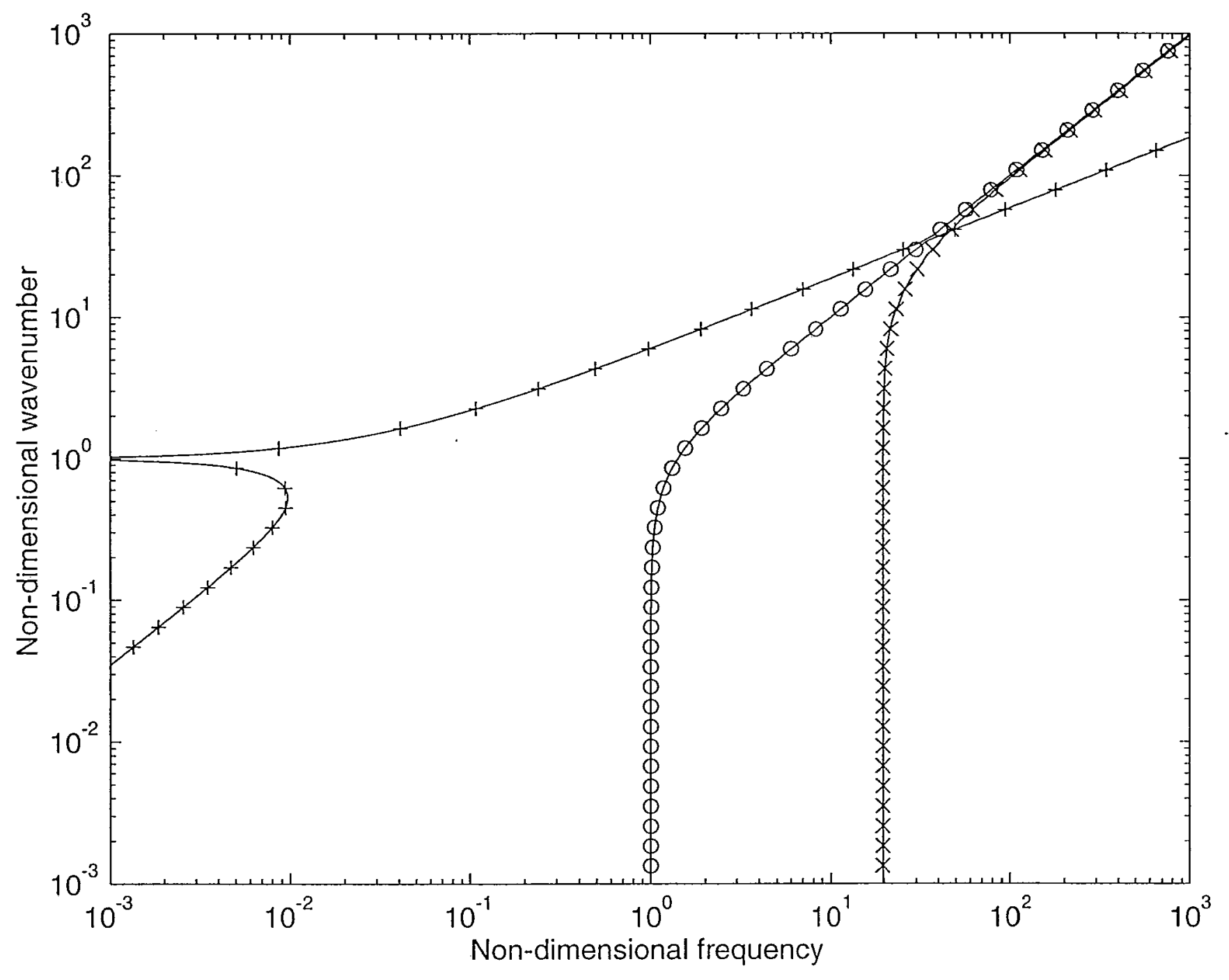




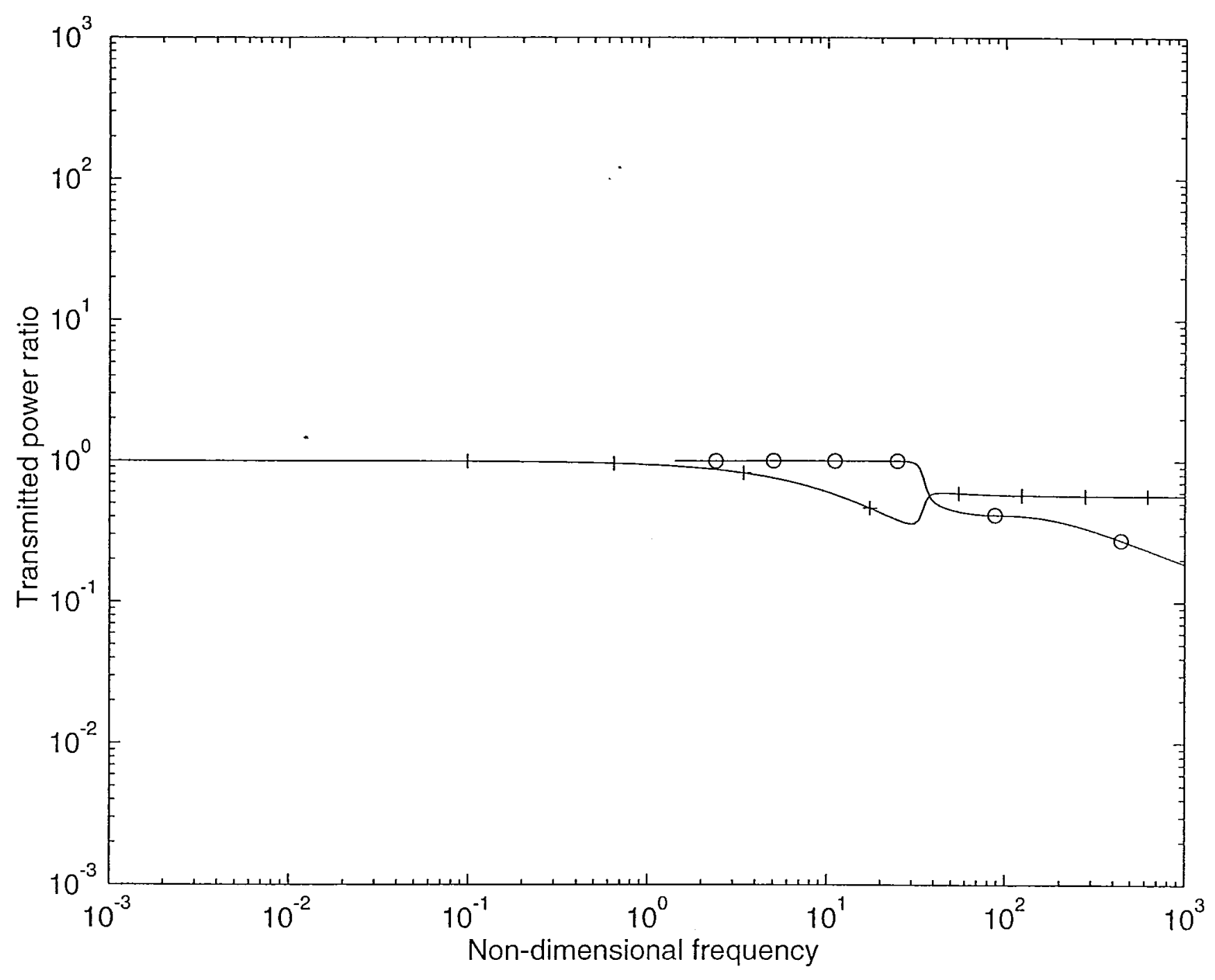

